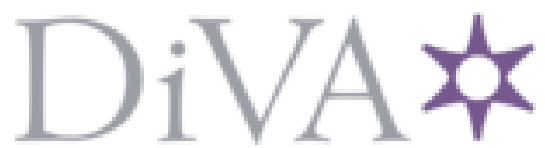

http://www.diva-portal.org

This is the published version of a paper published in Management Information Systems Quarterly.

Citation for the original published paper (version of record):

Sandberg, J., Holmström, J., Lyytinen, K. (2020)

Digitization and Phase Transitions in Platform Organizing Logics: Evidence from the Process Automation Industry

Management Information Systems Quarterly, 44(1): 129-153

https://doi.org/10.25300/MISQ/2020/14520

Access to the published version may require subscription.

N.B. When citing this work, cite the original published paper.

Permanent link to this version:

http://urn.kb.se/resolve?urn=urn:nbn:se:umu:diva-168603 


\title{
Digitization and Phase Transitions in Platform ORGANIZING LOGICS: EVIDENCE FROM THE PROCESS AUTOMATION INDUSTRY ${ }^{1}$
}

\author{
Johan Sandberg and Jonny Holmström \\ Swedish Center for Digital Innovation, Department of Informatics, Umeå University, \\ 87 Umeå, SWEDEN \{johan.sandberg@umu.se\} \{jonny.holmstrom@umu.se\} \\ Kalle Lyytinen \\ Weatherhead School of Management, Case Western Reserve University, \\ Cleveland, $\mathrm{OH} 44106$ U.S.A. \{kalle@case.edu\}
}

\begin{abstract}
This paper draws on complex adaptive systems (CAS) theory to explore the transformation of an analog automation product platform as it was infused with extensive and deepening digital capacities over a 40-year period. Our case demonstrates how the deepening digitization of components and functions drives complexity by connecting the platform to multiple social and technical settings and producing new interactions and information exchanges. The increased connectivity and dynamism invited unexpected and significant architectural and organizational shifts that moved the platform toward an ecosystem-centered organizing logic. CAS theory and its notion of constrained generating procedures (CGPs) are used to analyze how new connections and interactions produced a multilevel and nonlinear change in the platform organization. We offer two main contributions. First, we provide a novel empirical analysis of how product platform digitization leads to phase transitions and show the mediating role of three mechanisms in this process treated as CGPs: interaction rules, design control, and stimuli-response variety. Second, we demonstrate the multilevel and recursive nature of digitally driven growth in physical product platforms.
\end{abstract}

Keywords: Complexity, platform evolution, phase transition, platform change, digital transformation, digital innovation, product platform, platform ecosystem, digital control systems, internet of things

\section{Introduction}

The rapid pervasion of digital technology into physical products has become a prominent driver of complexity, pushing incumbent firms toward platforms and ecosystems (Yoo et al. 2012). Past studies suggest that increased digitization spurs

\footnotetext{
${ }^{1}$ The accepting senior editors for this paper were Bill McKelvey, Hüseyin Tanriverdi, and Youngjin Yoo.

(C)2020. The Authors. Published by the Management Information Systems Research Center at the University of Minnesota. This is an open access article under the terms of the Creative Commons Attribution CC BY License, which permits use, distribution, and reproduction in any medium, provided the original work is properly cited.
}

change in a firm's organizing logic by instilling new properties into product platforms (Gawer 2014; Lee and Berente 2012; Svahn et al. 2017). "Organizing logic" refers to how the firm designs, manufactures, and distributes its products and derivative services; the reasons it offers product functions or services; and the rationale for related organizational arrangements (Sambamurthy and Zmud 2000; Yoo et al. 2010). However, how infusion with digital components generates emergent product platform properties that drive complexity and transitions in the firm's organizing logics has received little attention. To fill this gap, we explore the dynamic of continued embedding of digital capacities and how it changes the scale and scope of a product platform's functions, resulting in punctuations in the firm's organizing 
logic. We specifically address the following question: How is increased digitization implicated in product platform transitions and related organizing logics?

Drawing on complex adaptive systems (CAS) theory, we hypothesize that digitization induces platform transitions via an emergent change in its architecture (Kretschmer and Claussen 2016). This dynamic differs starkly from incremental linear change in traditional analog products, related ecosystems, and associated organizing logics (Cusumano et al. 1992). CAS theory provides a robust framework for our analysis because it addresses endogenous change in product systems that result from emergent interactions within them and in their environment. We build on Holland's (1998) concept of constrained generating procedures (CGPs), that is, networks of relatively simple rules or mechanisms that interactively generate emergence in complex systems and produce transitions from one systemic state to another. We particularly examine how digitization changes CGPs linked to product platforms and triggers new system-level organizing logics. For this, we apply Hughes's (1983) concept of the reverse salient: ongoing digitization of product platforms' components and/or relationships that block the product platform's growth in scale or scope. Through digitizationdriven resolution of a series of reverse salients, cumulative digital capacities are introduced into product platforms, and they act as "strange attractors" that continue to drive platform reorganization and expansion.

The conceptual scaffolding is applied in an exploratory longitudinal case study on product platform change in a leading process automation manufacturer (ABB) between 1983 and 2016. We trace cumulative effects of successive waves of digitization on ABB's automation platform by charting changes in its architectural designs and ensuing shifts in the firm's organizing logic. During this process, ABB transformed from a solely physical product manufacturer to a producer of versatile hybrid physical-digital systems and engaged in an increasingly rich range of interactions in a growing ecosystem with its associated value logics.

\section{Digitization and the Dynamics of Product Platforms}

\section{Platform Types and Change}

Platform research is now voluminous, diverse, and crossdisciplinary and comes with a wide array of concepts (McIntyre and Srinivasan 2017). This study addresses transitions in product platforms and their temporal and logical dependencies. We build on Gawer's (2009, p. 59) suggestion that platform types represent "stages of evolution of platform development." Although some studies offer valuable insights into such changes and their drivers (e.g., Lee and Berente 2012; Svahn et al. 2017), they do not account for how cumulative technological and organizational change over extended periods manifests in platform change or how such evolution triggers shifts in a firm's organizing logics (Gawer and Cusumano 2014). Scholars have generally found that as firms introduce digital elements, they open up their products or services and, by doing so, they move from an internal production-oriented logic to an external supply-chain innovation logic (Thomas et al. 2014). However, how digital technologies spur such change has received limited attention. We focus specifically on conditions under which expansive digitization transforms product platforms and related organizing logics. This calls for a platform taxonomy that distinguishes between platform types and associated organizing logics (Thomas et al. 2014). We draw on Gawer's (2014) classification, which recognizes central features of a spectrum of platform types from a physical product platform to a digital multisided platform ecosystem, with various intermediate hybrid configurations (Table 1).

Product platform literature originates from studies of engineering and design of industrial products. Product platforms comprise families of stable shared assets that enable firms to produce customized derivatives of products for specific markets and niches more quickly and cheaply (Meyer and Lehnerd 1997; Robertson and Ulrich 1998; Wheelwright and Clark 1992). Such assets include product components, processes, market knowledge, people, and their relationships: "the technical architecture of the product or service - as well as the structure of the underlying capabilities" (Thomas et al. 2014, p. 203). Platform ecosystems literature, which mainly originates in economics and strategy studies, defines a platform as "a modular structure that consists of tangible and intangible components (resources) and facilitates the interaction of actors and resources (or resource bundles)" (Lusch and Nambisan 2015, p. 162). This stream focuses on the strategic and economic effect of controlling (shared) resources that enable new value-creating interactions among participants founded on an evolving technological system (Constantinides et al. 2018; Karhu et al. 2018; Parker and Alstyne 2018). Research in this area has addressed the design of architectures (technological systems) and the economics of interactions facilitated by associated governance (e.g., governance rules and boundary resources). Per Tiwana et al. (2010), architecture partitions a platform "into a relatively stable platform and a complementary set of modules that are encouraged to vary, and the design rules binding on both" ( $p$. 677), and governance refers to "who makes what decisions about a platform" (p. 679). 


\begin{tabular}{|c|c|c|}
\hline Characteristic & Internal Product Platform & Platform Ecosystem \\
\hline Description & $\begin{array}{l}\text { Platform as the stable center of a } \\
\text { product family leading to derivatives. }\end{array}$ & $\begin{array}{l}\text { Platform as a system architecture that supports a collection } \\
\text { of complementary assets for extended value creation and } \\
\text { extraction across multiple actors. }\end{array}$ \\
\hline Key constructs & $\begin{array}{l}\text { Product family; architecture; economies } \\
\text { of scope, modularity; commonality. }\end{array}$ & $\begin{array}{l}\text { Network externalities; complementarities, innovation; } \\
\text { standards; modularity. }\end{array}$ \\
\hline Level of analysis & $\begin{array}{l}\text { The firm, and (for a semi-open product } \\
\text { platform) supply chain participants. }\end{array}$ & The platform and its evolving ecosystem. \\
\hline $\begin{array}{l}\text { Constitutive } \\
\text { agents }\end{array}$ & $\begin{array}{l}\text { Agents within the firm or external agents } \\
\text { contracted for a specific purpose. }\end{array}$ & $\begin{array}{l}\text { Unbounded and dynamic set of agents, individuals, or firms } \\
\text { that interact for value creation in various, shifting roles. }\end{array}$ \\
\hline $\begin{array}{l}\text { Nature of } \\
\text { interfaces }\end{array}$ & $\begin{array}{l}\text { Fixed and semi-closed (not disclosed } \\
\text { externally), one-to-one mapping. }\end{array}$ & Dynamic and open or semi-open, many-to-many mapping. \\
\hline $\begin{array}{l}\text { Accessible } \\
\text { digital } \\
\text { capabilities }\end{array}$ & $\begin{array}{l}\text { Within the firm, supply chain, or selected } \\
\text { allies. }\end{array}$ & $\begin{array}{l}\text { Within the ecosystem constrained by IP, governance, and } \\
\text { build-up of boundary resources. }\end{array}$ \\
\hline Architecture & $\begin{array}{l}\text { Integration of key functional elements. } \\
\text { Early design decisions ripple through the } \\
\text { development (i.e., early choices remain } \\
\text { strongly inscribed in later designs). }\end{array}$ & $\begin{array}{l}\text { Bundling of core resources facilitates interactions with and } \\
\text { integration of foreseen and unforeseen agents/resources. } \\
\text { Emergent design with frequent adaptations as combinatorial } \\
\text { options arise and are discovered. }\end{array}$ \\
\hline $\begin{array}{l}\text { Governance and } \\
\text { control }\end{array}$ & $\begin{array}{l}\text { The platform owner retains decision } \\
\text { rights on what and how modules do } \\
\text { what they do, and interfaces define } \\
\text { boundaries. }\end{array}$ & $\begin{array}{l}\text { The platform owner defines boundaries and openness of } \\
\text { interfaces, what and how modules do what they do through } \\
\text { varying degrees of output, process and input control. } \\
\text { Agents are affected by rules but can engage in autonomous } \\
\text { decision making and action. Significant bidirectional control }\end{array}$ \\
\hline $\begin{array}{l}\text { Value } \\
\text { proposition }\end{array}$ & $\begin{array}{l}\text { Scale and scope economies for internal } \\
\text { production. } \\
\text { Platform investments shared across } \\
\text { derivatives. Internal value transfer } \\
\text { mechanisms. }\end{array}$ & $\begin{array}{l}\text { Scale and scope economies in the value system. } \\
\text { Complementarities provided by open innovation by } \\
\text { unforeseen actors (open source, crowd). } \\
\text { Multisided markets through shared platform co-create and } \\
\text { extract value. }\end{array}$ \\
\hline $\begin{array}{l}\text { Exemplary } \\
\text { publications }\end{array}$ & $\begin{array}{l}\text { Meyer and Lehnerd 1997; Robertson } \\
\text { and Ulrich 1998; Simpson 2004; } \\
\text { Wheelwright and Clark } 1992 .\end{array}$ & $\begin{array}{l}\text { Bresnahan and Greenstein 1999; Eaton et al. 2015; Lusch } \\
\text { and Nambisan 2015; Parker et al. 2017; Tiwana et al. } 2010 .\end{array}$ \\
\hline
\end{tabular}

Gawer (2014, p. 1245) regards all platforms as "evolving organizations or meta-organizations that: (1) federate and coordinate constitutive agents who can innovate and compete; (2) create value by generating and harnessing economies of scope in supply or/and in demand; and (3) entail a technological architecture that is modular and composed of a core and a periphery." Governance and architectural choices enable and constrain distinct sets of interactions among agents that shape the variety and intensity of a firm's interactions with its environment. By affording varying levels of platform openness and new types of information exchanges, digitization modifies participant agents' behaviors, interactions, and scope, thereby transforming (gradually or radically) related organizing logics. Options created by digitization typically shape the diversity and volume of participating agents and the coordination and control of their actions. For (internal) product platforms, agents are primarily located within the platform-owning firm, and information exchanges primarily occur within the firm or its immediate supply chain, with clearly discernible constraints, that is, interactions are rooted in a managerial hierarchy and stable contractual relations. In a platform ecosystem, diverse agents such as competitors, complementors, and users interact through a platform open to a wide range of exchanges and interactions (see Karhu et al. 2018; Parker and Alstyne 2018). Such increased variation also creates new options for configuring value creation and appropriation (Gawer and Cusumano 2014). Economies of scale and scope change as product platforms move toward new ways of economizing transactions. Architectural characteristics such as the overall scope of platform functionality and openness of its interfaces dictate the range of innovation and production activities and what other agents are allowed or incentivized to do (Thomas et al. 2014). 


\section{Digitization and Platform Change}

Digitization has been recognized as a potent driver toward platform ecosystems (Parker et al. 2017; Yoo et al. 2012). It subjects product architectures to new design rules afforded by novel features of digital technology including reprogrammability, data homogenization, decoupling, and distributedness (Lyytinen et al. 2016). Reprogrammability enables continued, fluid expansion of a product's functional scope through programmable von Neumann architecture as long as new instructions conform to established rules and meanings of data (Kallinikos et al. 2013; Yoo et al. 2010). New capabilities can be added after initial product design, and new combinations of functions can be created through integration (e.g., by gateways and APIs). Data in digital products are homogenized in that information can be stored, transmitted, processed, and displayed on multiple devices and networks and integrated in infinite ways. Data from various sources can be processed by "general purpose" resources and recombined in novel ways when appropriate instructions are invented. Functionality is decoupled from material bearers due to reprogrammability (between devices and services) and data homogenization (separation between devices/networks and content). Finally, data and functions can be distributed across contexts as "transient assemblies of functions, information items, or components spread over information infrastructures" (Kallinikos et al. 2013, p. 360). These new design rules result in increasingly fluid product boundaries, increased heterogeneity of use, and expansion of architectural layers with multiple design hierarchies, product-agnostic components, and general standards promoting wider sharing of information (Lyytinen et al. 2016; Yoo et al. 2010). Although layered modular architecture and digital design rules putatively instigate a shift toward platform ecosystems (Constantinides et al. 2018), we know little about how endogenous technological change drives platform transitions or how sequences of novel phenomena happen when digital capacities are added to product platforms. We also know little about the factors that make such platform transitions likely or necessary.

\section{Platform Change as Change of Complex Adaptive System}

Ultimately, product platforms are complicated technical systems consisting of numerous product components and their relationships (Simpson 2004). They are complicated because interactions between components can and must be determined and predicted during product design irrespective of the volume of such components and interactions. A complex system, such as the production organization surrounding a product platform, in contrast, is "made up of a large number of parts that interact in a non-simple way" (Simon 1962, p. 468) and exhibits emergence: "the arising of novel and coherent structures ... during the process of self-organization" (Goldstein 1999, p. 49). In product platforms, emergence occurs in response to increases in complexity driven by digitization and its design rules, which organically and recursively shape how a product platform interacts with its social, market, and institutional environment. The complexity is manifested in changes in product platform features, enabled interactions, and related organizing logic (i.e., ways the product organization interacts internally and externally and organizes its operations). Overall, digitization triggers increases in variety and intensity in platform-mediated interactions, which ultimately result in a transition to a new organizing logic. Hence, we use CAS theory as an analytical lens to examine how the introduction of digital capacities and design rules create opportunities or necessities for transitions in organizing logics of product organizations.

CAS theory generally seeks to explain how importing energy and information into open systems generates "dissipative structures" via feedback loops, by which the system acquires emergent features (Anderson 1999; Nicolis and Prigogine 1989). In our setting, these new resources are digital capacities and associated new information, which result in new relationships and interactions. A consequent change in the product platform is viewed as an emergence of an alternative social order resulting from various feedback-based information and resource exchanges within a product platform and between the platform and its environment. Such change is called a phase transition when it involves a transformative shift in the company's organizing logic following shifts in the composition of its product platform.

Interactions among various agents (including design and use processes, related professions, industrial groups, and firms) jointly produce platform change and the emergence of associated order (Benbya and McKelvey 2006). According to CAS theory, these emergence-generating interactions are guided by networks of mechanisms expressed in CGPs, which operate in hierarchies where a basic CGP serves as a submechanism in a more complex one (Holland 1998). Changes in CGPs produce new behavioral patterns within and between agents that subsequently manifest in transitions in systemlevel behaviors, producing an alternative organizing logic. Thus, the generation, adoption, and diffusion of new knowledge and learning through new interactions enabled by GCPs trigger changes in product platforms (Benbya and McKelvey 2006). The process is influenced by types and levels of connectivity among agents (Morel and Ramanujam 1999) in four dimensions: diversity, adaptiveness, connectedness, and mutual dependencies (Page 2010). Diversity refers to degrees of variations among entities, adaptiveness to the respon- 
siveness of agents' schemata to new information from the environment when diversity grows, connectedness to the amount and level of couplings that govern information flows among agents, and mutual dependencies to the level of output interdependency between agents.

In product platforms, architectural and governance structures and knowledge bases largely determine these four features. Digitization creates new components, knowledge, and interactions, many from or between new external agents (Lee and Berente 2012; Yoo et al. 2010). Overall, digitization increases variety creation and deviation in product platforms through positive and negative feedback loops manifested, enabled by changing CGPs (Anderson 1999). As digitization increases, it significantly affects each of the features. Reprogrammability and incompleteness raise diversity and needs for adaptiveness and new knowledge. Decoupling and data homogenization permit new relationships between product components by reducing interdependencies and increasing connectedness, diversity, and adaptiveness.

Generally, as product organizations add digital capacities and launch new CGPs, they will oscillate between three regions of change: order, emergent complexity, and edge of discontinuity (Tanriverdi and Lim 2017). Order is treated as a closed, static system and is not considered here any further. In the region of emergent complexity, a change in CGPs produces new interactions with emergent and novel systemlevel phenomena, but the system remains focused as its core structures remain stable, while new schemata, connections, and potential for self-organization emerge gradually, driven by organic interactions and coevolution with amplifying change (Tanriverdi and Lim 2017). Performance in such states starts to "dance," that is, the product design and its environment can change unpredictably, reflected in shifts in agents' schemata and growing diversity (Tanriverdi et al. 2010). Our focus is on the edge of discontinuity, where the system faces a crisis manifested in a growing number of failures or inadequacies (Page 2010). These curb possibilities for functional progression of the product platform and its adaptation by blocking change in critical technological components (e.g., the introduction of a new electric car engine with a different type of digital control). In technology studies, triggering conditions for strange attractors (situations that can shift the whole system) have been called reverse salients, poorly performing subsystems that lag behind the advancing product performance frontier (Hughes 1983). For participating agents, a reverse salient is a "complex situation in which individuals, groups, material forces, historical influence, and other factors have idiosyncratic, causal roles, and in which accidents, as well as trends, play a part" (Hughes 1983, p. 79). Such situations prevent the fulfillment of a platform's evolutionary potential.
A reverse salient triggers a search for increase in diversity of product components and their relationships (Rosenberg 1969), which creates new "state spaces" for design. Removal of a reverse salient pushes a product and related organization at an edge of discontinuity toward novel explorations and creation of new CGPs. This phase comes with higher diversity, adaptiveness, connectedness, and changes in interdependencies that destabilize the product organization and its environment. The system may progress to a tipping point (Lamberson and Page 2012), where it transitions to a qualitatively different order involving deep changes in conventions, shared assumptions, and product functions and their logic. Emergent change follows removal of the reverse salient through deviationamplifying feedback loops. These CAS constructs provide an initial scaffolding (Table 2) for examining phase transitions associated with product platforms as a function of increased digitization resulting in new organizing logics.

\section{Research Site and Methods}

\section{Case Selection and Methods}

We conducted a longitudinal case study (Eisenhardt 1989) covering 35 years of digitization of ABB's product platform. This is a platform for automating production processes involving heavy physical machinery across various industries (e.g., pulp, mining, and energy). Automation product platforms offer ideal settings for studying long-term effects of digitization because of their capital-intensive nature, longevity (often $40+$ years), and central role in contemporary manufacturing. In the past four decades, extensive digitization has radically automated and changed the control of industrial processes. Automation product platforms are designed as general-purpose products and include numerous modules that can be flexibly assembled for site-specific applications. The systems operate in very demanding settings with a risk of significant environmental hazards. Accordingly, they must be robust, reliable, and capable of maintaining continuous operation.

We focus on the gradual expansion of the automation control system design because architectural principles facilitated by digital technologies were progressively embraced in ABB's products. Although it was initially designed solely to control local physical production processes, its evolution added many digital functions, resulting in a growing product scope that transformed both the product platform's nature and the firm's organizing logic.

Contemporary distributed control systems consist of sets of interconnected digital processing units that steer dynamic and 
Table 2. Complexity Concepts

\begin{tabular}{|c|c|c|}
\hline Construct & Description & $\begin{array}{c}\text { Potential Effects of Digitization } \\
\text { of Product Platforms }\end{array}$ \\
\hline $\begin{array}{l}\text { Phase } \\
\text { transition }\end{array}$ & $\begin{array}{l}\text { Structural change when a system (product organization) } \\
\text { passes from one region of complexity to another } \\
\text { (Benbya and McKelvey 2006). A phase transition is } \\
\text { dissipative because structures and associations in the } \\
\text { system change and new ones emerge (Nicolis and } \\
\text { Prigogine 1989). Here, it involves transitions in the focal } \\
\text { company's organizing logic associated with shifts in the } \\
\text { composition of its product platform. }\end{array}$ & $\begin{array}{l}\text { Digitization challenges product organizations to } \\
\text { revise strategies, innovate, and restructure } \\
\text { products (Henfridsson and Yoo 2014; Svahn et } \\
\text { al. 2017). }\end{array}$ \\
\hline $\begin{array}{l}\text { Constrained } \\
\text { generating } \\
\text { procedures } \\
(\mathrm{CGP})\end{array}$ & $\begin{array}{l}\text { Interaction rules with propensity for distinct types of } \\
\text { emergence. CGPs are networks of mechanisms that } \\
\text { generate variety from inputs, actions, and information } \\
\text { coupled to a set of constraints. The networks are fixed } \\
\text { or transitional (linkages are created and dissolved by } \\
\text { mobile agents) and operate in hierarchies where basic } \\
\text { CGPs serves as mechanisms in a more complex CGP } \\
\text { (Holland 1998). }\end{array}$ & $\begin{array}{l}\text { The malleability of digital technology allows } \\
\text { agents to create and dissolve linkages among } \\
\text { components and agents (Benbya and McKelvey } \\
\text { 2006; Eaton et al. 2015). }\end{array}$ \\
\hline Connectivity & $\begin{array}{l}\text { Connectivity shapes the system's propensity for emer- } \\
\text { gent behaviors through diversity, adaptiveness, con- } \\
\text { nectedness, and mutual dependencies. Diversity refers } \\
\text { to qualitative differences among entities. Adaptiveness } \\
\text { reflects the extent to which actors change their schemas } \\
\text { based on feedback. Connectedness measures coup- } \\
\text { lings governing flows of information and resources } \\
\text { among agents. Mutual dependencies capture inter- } \\
\text { dependencies of outputs between agents. }\end{array}$ & $\begin{array}{l}\text { Digitization increases connectivity without } \\
\text { imposing tight couplings where agents are } \\
\text { affected by emergent interaction patterns in the } \\
\text { internal and external systems, new types of } \\
\text { couplings, and different types of interdepen- } \\
\text { dencies (Lee and Berente 2012; Lusch and } \\
\text { Nambisan 2015). }\end{array}$ \\
\hline $\begin{array}{l}\text { Reverse } \\
\text { salient }\end{array}$ & $\begin{array}{l}\text { Any subsystem that lags behind in the development of } \\
\text { the technological system because of insufficient } \\
\text { performance and hampers the whole system's } \\
\text { performance. }\end{array}$ & $\begin{array}{l}\text { Reverse salients emerge during digitization } \\
\text { when a product organization is challenged by } \\
\text { trade-offs between backward compatibility } \\
\text { (limited technical improvements) and demand } \\
\text { for an architectural break to radically improve } \\
\text { performance (Kretschmer and Claussen 2016). }\end{array}$ \\
\hline
\end{tabular}

continuous manufacturing processes based on predetermined events (e.g., changes in flow rate or temperature). They are organized hierarchically in layers, and many functions are allocated to programmable logic controllers (PLCs) that are placed in production environments to steer process steps. At the lowest (process) level, sensors and actuators record signals and transmit them to controllers with real-time responses dictated by preprogrammed logic. These signaling actuators execute commands that change the state of the process. This happens in milliseconds because the system must respond to any process changes swiftly to maintain control. Communication networks connect controllers for system-level monitoring and coordination, including analyzing event histories and orchestrated responses to multiple interactive changes based on model predictions. Thus, process data are integrated hierarchically and the highest-level subsystems provide over- all process control and diverse kinds of information for human operators, including typical enterprise applications, such as tracking stock levels, production and maintenance schedules, production volumes, cost estimates, and quality parameters.

As shown in Table 3, we collected data in two periods (2007-2010 and 2011-2017) through interviews, participant observation, and searches of archival data. Indications of product platform transitions triggered by digitization prompted an exploratory case study (Eisenhardt 1989). In a first phase, we observed a project to manage the installed base of automation systems at various customer sites; in a second phase we followed a project to increase certified solutions from third-party developers. This called for mapping the product platform's historical evolution (see Appendix A for details). 
Table 3. Data Collection Summary

\begin{tabular}{|l|l|l|l|}
\hline \multicolumn{1}{|c|}{ Data Source } & \multicolumn{1}{c|}{ Period 1 } & \multicolumn{1}{c|}{ Period 2 } & \multicolumn{1}{c|}{ Total } \\
\hline Interviews & 14 & 9 & 23 \\
\hline Participant observation & 5 occasions (17 hours) & 12 occasions (66 hours) & 17 occasions (83 hours) \\
\hline Archival data & $\begin{array}{l}\text { Project descriptions, technical specifications, annual reports, life-cycle and market analyses, } \\
\text { and product pamphlets (56 documents, approximately 3900 pages). }\end{array}$ \\
\hline
\end{tabular}

We adopted a process perspective (Van de Ven 1992) because our initial familiarization with the data revealed path dependencies and long-term cumulative change as salient themes. We applied inductive procedures in three steps to identify patterns of change over time (Van de Ven 1992). Each step included multiple iterations of data reduction, theoryinformed conceptualizations, and triangulation (Langley 1999). The iterations allowed us to triangulate findings empirically and theoretically and clarify and focus on emerging themes (Miles and Huberman 1994).

First, we open-coded the data to discover key categories and their properties that characterized platform change (Charmaz 2006). This yielded more than 600 codable moments where change, its source, or its outcome were identified as sensitizing concepts to organize for subsequent refinement (Bowen 2006). We identified multiple themes indicating the presence of mechanisms and adaptation strategies. These were further refined by assessing their internal homogeneity (coherence within themes) and external heterogeneity (clear and identifiable distinctions) (Patton 1990).

Second, through temporal bracketing, we structured the analysis around periods of product continuity and discontinuity to allow theorizing of feedback mechanisms, mutual shaping, and multidirectional causality (Langley 1999). We identified four evolutionary phases demarcated by transitions in the product platform, each of which was operationalized as a radical change in the product platform's organization involving implementing a new architecture or opening an external resource inflow associated with organizational change. To this end, we formulated a matrix to display and compare key characteristics of the phases.

Third, we focused on identified phase transitions, then applied the four sensitizing dimensions of connectivity (diversity, adaptiveness, connectedness, and mutual dependency) as analytical filters across the coded instances to identify drivers of change in each transition. After filtering and categorizing, we identified 225 instances of change, then reviewed if and how alterations in the dimensions were associated with product platform change. As a result, we generalized such patterns into three generative mechanisms (CGPs), that is, causal structures that produced observable emergent features through macro-micro-level interactions (Hedström and Swedberg 1998; Henfridsson and Bygstad 2013). We then challenged this rendition by evaluating conceivable alternatives, their grounding in the data (Appendix B), and their role in phase transitions (see Table 4 later in this paper). Finally, we labeled the three mechanisms (CGPs) interaction rules, design control, and stimuli-response variety and analyzed their role in transitions.

\section{Digitization and Phase Transitions in ABB's Product Platform}

In the evolution of ABB's product platforms (Figure 1), digital capacities triggered change across multiple social and technical levels and environments, resulting in three platform transitions offering generalizable insights informed by complexity theory. In each new platform version, functions expanded to higher levels in the Purdue Reference Model (PRM, see Appendix C) as new nodes with novel digital capabilities were added. The increases in scope and openness of interfaces changed the platform's adaptability and capacity to tame complexity. Evolutions between generations were prompted by the platform's inability to cope with tensions stemming from a reverse salient that could not be addressed within the current product architecture. Here we review the four platform phases (Appendix D) and then use CAS theory to review deviation-amplifying mechanisms involved in the transitions as the reverse salient was resolved through digitization. This modified prevailing CGPs and drove the firm toward a new organizing logic.

\section{3-1992: Modular Architecture and Device Digitization}

In $1983,{ }^{2}$ ASEA released the Master product platform with a modular architecture and digital components in production

\footnotetext{
${ }^{2}$ In 1988, ASEA merged with Brown Boweri, forming ABB, the world's largest supplier of electro-technical equipment, with an approximately $20 \%$ share of the $\$ 50$ billion global electric power market, and about 180,000 employees.
} 


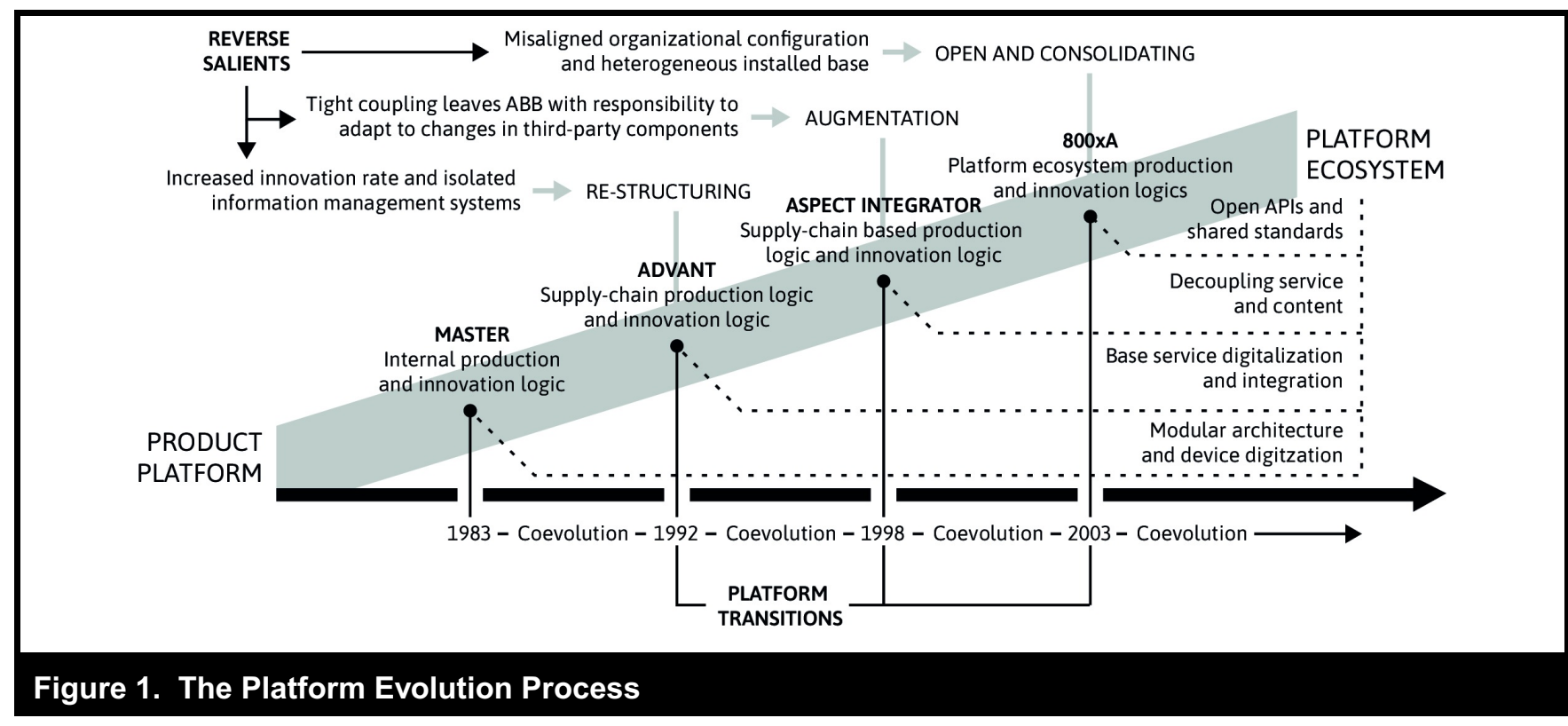

process control. Data homogenization introduced loose couplings between devices and the network by reducing complicated physical interface designs, thereby increasing connectedness and diversity in the system. Both hardware and software components were almost exclusively developed internally, but technological advances in the IT industry were rapidly increasing the affordability and utility of external digital solutions. Retaining competitive in-house development of all process automation components and solutions became increasingly challenging. Eventually, tight coupling of data and services and sole use of proprietary components formed a reverse salient hindering innovation and more efficient integration of components and solutions across automation systems. Reliance on market selection mechanisms for noncore components would help cut costs and reduce technological uncertainty. Services were becoming an increasingly important revenue source, so refocusing resources toward core process automation and complementary informationbased services emerged as a key strategic thrust. Reuse of functional engineering solutions, enabled by a more loosely coupled digitized design, would create a versatile integrated engineering environment:

We wanted to construct a common environment, a lot of this is the same data that you need to transfer between these systems: CAD, electricity, instrument databases, etc. All such data transfer was done manually, it was hard to keep it updated across systems. Then we felt, this is really added value that we should do and something we have the com- petency for, otherwise someone else is going to do such system integration. (R\&D Manager ABB)

\section{2-1999: Base Service Digitization and Integration}

In 1992, ABB released a new product platform, Advant OSC. It addressed the reverse salient by introducing an internal repository for integration of process data and a loosely coupled object-oriented software architecture that expanded product boundaries upward in the PRM hierarchy. The platform was augmented with new functionalities for plant-wide automation, manufacturing zone engineering, and data provisioning at the enterprise level. It increased connectedness, diversity, and adaptiveness and decreased interdependencies between service and device. The shift in the organizing logic focused on core process automation functionality and leveraged new external agents in the design and manufacture. The new architecture expanded the scope and openness of platform control points by using open communication standards, relying on commercial off-the-shelf solutions (COTS) such as Unix OS and HP hardware, and integrated data from third-party suppliers. However, ABB still controlled and developed basic process control-level hardware and software internally. The integration of all process data into a single database enabled new informationbased services. Over time, the increased connectedness created new mutual dependencies due to tight coupling between external information systems and the database. This 
gradually grew into a reverse salient, because $\mathrm{ABB}$ had to tweak its product configurations for each interface to adapt to related novel information flows from connected systems. This hindered digital service innovation because further integration would exacerbate needs for adaptation in external components:

A couple of years after releasing Advant we ran into trouble. The system integrated data, but we couldn't get other actors to change their data format, so we had to assume responsibility for data storage for a lot of external systems .... we wanted to develop the functionality, but in doing so, we assumed responsibility for developing other actors' components. We realized pretty soon that it wasn't sustainable. (R\&D Manager, ABB)

Adaptiveness was increased by opening the system interfaces. This challenged not only perceptions of the nature of the architecture but also the organizing logic:

We developed APIs for our system and an adaptation module that could hook into other systems' APIs. We started thinking that this idea of holding information together was interesting for a lot of actors, not only engineers .... At first, we thought we were developing an integration platform for engineering tools, then for connecting all the parts of the control system, then to integrate different products and units in $\mathrm{ABB}$, and eventually to integrate the whole world. (R\&D Manager, ABB)

\section{9-2003: Decoupling Service and Content}

In 1999, ABB introduced the Aspect Integrator Platform as a part of its strategic initiative "Industrial IT." The initiative pursued a common architectural standard for all of ABB's digital product solutions by leveraging Aspect Integrator's integrative capacity and providing certified compatible automation solutions - developed both in house and externally - for various areas with high reliability. This was expected to enable ABB to create CGPs that leveraged Aspect Integrator's capacity for diversity generation by incorporating more diverse external agents, but still aptly constrain these procedures. Although a relatively vague visionary concept, Industrial IT rapidly turned into a strategic pivot in ABB because of contextual conditions and amplifications for diversification offered by technology. The goal was to increase diversity, connectedness with external agents and between the different automation solutions, and amplify adaptiveness. In 2000 , the automation division's director declared, "Industrial IT is the future. Within a year, all products from my division must be Industrial IT-certified." Many units responded enthusiastically, but an R\&D manager responsible for the concept noted that nobody really knew what the certification meant. $^{3}$ The certification grew rapidly in ABB: 1100 products were certified in 2002, and a year later $35,000{ }^{4}$ During this period, the organization's identity changed as process automation concepts and Industrial IT became central to the firm's transformation into a digital company:

We are transforming our business portfolio ... incorporating sophisticated software applications. We apply our expertise to develop creative ways to integrate our products and systems with our customers' business processes to enhance their productivity and efficiency. We refer to this integration as "Industrial IT." Our increased commitment to Industrial IT has been supported by our recent strategic initiatives and our research and development efforts. Collaboration with our customers and our commitment to Industrial IT will be further enhanced by the realignment of our business operations. (ABB 2001, p. 5)

ABB also explored options to expand product boundaries using Aspect Integrator and Industrial IT and expand its integration offerings from process automation to other business processes and industrial settings. The organizing logic expanded to coordinate distributed agents and diverse technological components through integrative capacity and compatibility policies. Identity was transformed toward information-intensive business enabled by the Industrial IT architecture and realigning operations along customer segments. This ambitious strategy was abruptly stopped in 2002 when ABB faced severe financial problems due to an acquisition spree, economic recession (dot-com bust), and mounting asbestos claims. The firm had to focus on core businesses and divest a significant portion of the company. During this period, the platform was migrated to multiple operating systems and accrued substantial technical debt. Maintaining versions for all OSs and ensuring component compatibility became increasingly challenging, error-prone, and costly (a reverse salient). ABB had to revert its focus, divest a significant portion of the company, and consolidate the architecture by solely building on Windows OS in future products.

\footnotetext{
${ }^{3}$ For example, as the IT manager of the power division (with no software at any level of the scheme) wanted to participate, level 0 certification was added, defined as availability of all relevant information about a product (i.e., service manuals, maintenance information, user manuals, calibration information, etc.) in a digital format.

${ }^{4}$ Many of these at the lowest level: "Each certified product is assigned to a product suite and is named according to what it does and how it fits into the Industrial IT system" (ABB 2003, p. 26).
} 


\section{3-2017: Toward a Platform Ecosystem}

In $2003 \mathrm{ABB}$ released a new product platform based on the Aspect Integrator architecture called 800xA. It changed ABB's product strategy and organizing logic by packaging all incremental innovations and new components inherited from previous years into a single architecture. This positioned $\mathrm{ABB}$ as a full integrator and service provider for automation systems in industrial environments with a large number of complementors. The 800xA increased diversity by expanding connectedness between product components horizontally by enabling plant-wide data integration and vertically by creating enterprise system level couplings, and laterally toward other IT systems through the increased use of COTS interfaces (such as SAP/R3) and industry standards. Because of rise in the use of third-party products and reliance on open standards, 800xA was profoundly affected by changes in the external IT environment. This called for continued maintenance and adaptation (interdependencies requiring adaptiveness). Rapid, continual innovation resulted in growing diversity through technological solutions, making existing components obsolete and incompatible. Digitization expanded functionality but increased environmental variability and reduced reliability and transparency, which conflicted some top priorities in production environments: safety, minimizing environmental risks, and avoiding costly downtime:

You don't want to install updates, that's a disturbance, and there are always risks involved with installing updates. We minimize updates and only make software changes when there are obvious problems or the version of Windows is so old that it's not supported anymore. I can't recall us updating because we needed new functionality. (IT Manager MineCo)

Production ultimately depends on mechanical systems that constrain possible efficiency improvements, so clients' incentives for increasing software functionalities were limited. Instead, ABB sought to increase diversity by adding functionalities for data analysis. For example, in 2017 ABB launched a complimentary augmentation service, ABB Ability, described as a business channel facilitating access to the installed base of solutions for suppliers and customers with certified solutions for analyzing operations. ${ }^{5}$ The decision to open access to extracted data, rather than platform services, is in line with the risk-averse context and experience gained from previous phases of automation system design:

\footnotetext{
${ }^{5} \mathrm{An}$ "Industrial Internet technology platform and cloud infrastructure. An open, globally available, digital-industrial ecosystem for customers, partners, suppliers and developers" (www.abb.com).
}

When designing the Aspect Integrator Platform and organization around Industrial IT we wanted to build an ecosystem .... We later realized that opening up too much towards the actual process was a big risk towards the market and customers. Even if you certify and test, you might have unexpected failures and breakdowns .... In an App Store, even with just 500 external apps, testing all permutations becomes challenging. We do regression tests whenever Microsoft has a security update or we need to fix a bug. So how can we make sure that the core is not affected? External apps probably need to operate in the external environment. (R\&D Manager ABB)

\section{Digitally Induced Mechanisms (CGPs) and Phase Transitions}

Our analysis reveals several recursive patterns of change. Implementing digital capacities to address reverse salients created new CGPs that fostered continued increases in the number and diversity of agents interacting with the platform and their interconnectivity. Digitally induced change was mediated by three deviation-amplifying mechanismsCGPs - that jointly enabled and triggered transitions: (1) changes in interaction rules, (2) distribution of design control, and (3) increases in stimulus-response variety. These CGPs pushed the system to an edge of discontinuity and to transition into a new organizing logic three times. The process was characterized by emergent change and nonlinear cumulative effects. Changes originally perceived as innocuous technology amendments later proved to have deep consequences. Digitization scaled product platform functions upward toward customer operations and related interactions, expanded information exchanges, and increased the number of participating agents.

Changes in Interaction Rules: Introduced informationbased couplings profoundly affected interactions enabled and constrained by the platform architecture. The couplings separated data from unique physical features of designed components and their connections by homogenizing internal data into information-based connections expressed in binary form. This enabled the use of general-purpose digital technologies to store, transmit, process and display process data. The decoupling generated munificent combinatorial options not possible in earlier systems. Information-based couplings exponentially increased the numbers of connected elements and system variety (connectedness and diversity). We refer to this mechanism as a change in interaction rules, which results from the increase in the number of (loosely) connected elements after implementing digitally enabled interactions. 
The changes in interaction rules need to be viewed in the light of ABB's persistent challenge to increase the integrative capacity while retaining control to maintain security in riskavoidant production processes. To ensure high reliability, ABB needed to carefully consider the positioning of control points that would allow isolating the production process and verifying compatibility.

Our customers are terrified about opening up here [the production process], they even keep their own IT departments away from it although there are a lot of servers, clients, etc. Security, reliability, consistency, and real-time properties are extremely important. If we compromise on that, then it is goodbye, our customers are not interested anymore. (R\&D Manager ABB)

Due to this priority, adaptations in interaction rules increasing diversity and connectedness were implemented gradually. First, information-based couplings replaced one-to-one mappings in the physical transport layer with many-to-many couplings by standardized physical data transfer protocols and interfaces. This vastly expanded combinatorial options to trace and monitor production processes and allowed prefabricated hardware modules to provide greater diversity and connectedness in system control. The ability to combine data from multiple sources increased the number of connected elements and enabled a single controller to integrate data from many sources and expand system control functions. By the early 1990 s, a new reverse salient surfaced when mutual dependencies from the tight data-service coupling, internal component development, and proprietary interfaces limited combinatorial options to reuse logical level engineering solutions (libraries, configurations, etc.) and integrate data. $\mathrm{ABB}$ restructured its design rules and launched a new architecture to ease integration and control of system functionalities and abstracted them to software services. The loose coupling of services and devices increased the number of connected elements and created new connections to external components. Thus, object-oriented architecture, open standards, and data integration from external components moved ABB from an internally focused organizing logic toward leveraging external components in an increasing orientation to system maintenance and engineering services.

Before that, we designed and manufactured all components by ourselves, operating system, database, graphics hardware, and software. Everything, all by ourselves. We realized that it wasn't sustainable, we needed to change. So, in 1992 we introduced the new architecture, based on Unix and hardware from HP for workstations. It was a radical change at that level of the process automation hierarchy. (R\&D Manager ABB)
Over time, the tight couplings to content in external components exposed significant mutual dependencies and hindered further integration because the platform had to ensure full compatibility with all external systems and their changes. To address this reverse salient, ABB's next architecture introduced novel couplings with low levels of mutual dependencies. Physical objects were digitally represented by "aspect objects" linking to relevant information (drawings, temperature, control panels, etc.). These couplings made the product platform's boundaries fluid and challenged the firm's identity. The Aspect Integrator expanded integrative capacity toward a greater variety of data sources that were no longer restricted to process automation (increased diversity, connectedness, and adaptiveness). The number of connected elements rose quickly (already 35,000 certified products in 2003). The new options to connect devices and combine data led $A B B$ to question the platform boundaries and probe possibilities of expanding into new industries using the Industrial IT concept. These integrative capabilities were seen as foundational for a deeper transformation in organizing logic and identity:

Through its engagement in Industrial IT, ABB aims to do for industry what Microsoft did for the office environment, combining productivity tools in packages, all the way from process automation to business automation. (ABB executive committee member, cited in ABB Review 2001, p. 22)

However, negative feedback from the external system (the burst of the dot-com bubble) and the rise of new internal constraints (the financial crisis following the acquisitions and asbestos crisis) dampened the system-expanding effects of CGPs. But the transition to many-to-many relations in components remained the foundation for generating new growth in diversity and connectedness. With the 800xA, the number of supported protocols for not only production environments but also plant-level systems and enterprise environments grew considerably (e.g., IEC61850, WirelessHart), increasing diversity, connectedness, and need for adaptiveness. These extensions not only removed some interdependencies but added some new ones.

In summary, digitally enabled interactions, facilitated by malleability, data homogenization, and decoupling of content from service and physical devices, increased connectedness and diversity and reshaped mutual dependencies. Information-based couplings allowed platform owners, users, and component developers to expand searches for combinatorial options among new elements, facilitating the discovery of novel forms of value creation. Such new rules accelerated platform change by promoting faster and broader spread of digitization. Information-based couplings loosely coupled previously tightly coupled components and identified and 
removed inefficiencies expressed in a reverse salient. The combinatorial options resulted in scope extensions and increased integrative capacity, which was advantageous for innovation and efficiency. However, changes in connectedness had to be balanced with security concerns in the riskaverse context. When information-induced perturbations exceeded the system's coping capacity and possibility for control, operational risks rose in ways that could cascade proposed solutions into chaos.

Distribution of Design Control: Digitization led to a gradual release and distribution of design control in each new version of ABB's product platform. This recurrently triggered emergent changes that challenged the prevailing organizing logic. Distribution of control altered diversity, called for adaptiveness, and created new interdependencies. The hybrid cyberphysical nature of automation systems generated tensions related to temporal differences in the growth of diversity and adaptiveness among digital and physical product components. Digital component developers were more distributed and had little or no connection to specific use contexts of process control with unique physical components. They could innovate more freely without significant centralized control, and their innovations could be accessed through digital channels at arm's length without significant physical interactions.

We refer to this mechanism as distribution of design control, defined as the decentralization of design rights to heterogeneous agents interacting with the platform. The distribution is enabled by the digital design rules and related structural composition of digital objects. This enabled fluidity (reprogrammability) in services and data processing and created dynamic relations between digital objects (because of the separation of content and services). In digital components functions, interfaces, and use rules could be readily edited, reconfigured, and recombined by agents with some decision rights, if sufficient openness to design components was granted. These properties enabled continuous reconfiguration of decision rights over components that granted external agents higher degrees of freedom for recombining components and system assemblies. The relative speed and ease of recombination increased product variability (i.e., dynamics and variety of elements and their couplings within and across products in use), heightening diversity and connectedness and calling for increased adaptiveness within the system.

The Master product platform increased diversity and need for adaptiveness at production sites through information-based coupling, but it did not diversify decision rights regarding the design and manufacturing of platform components much. Because development was kept in-house, diversity remained low in terms of output and innovating agents. However, the loose information coupling in the Advant platform increased diversity and connectedness by reconfiguring decision rights on the supply side. As new types of process data were integrated into a single database, ABB had to adapt to changes in the external systems providing data. This increased diversity called Advant to migrate across multiple OSs (HP-UX 8.x;9.x;10.x, Digital Unix, Open VMS, Windows NT) and progressively embrace general communication standards, continuing to distribute decision rights and increasing variability.

The transition to the Aspect Integrator platform was tightly linked to "the transformation of the $\mathrm{ABB}$ group into a knowledge- and service-based company" (ABB 2000, p. 2). The change sought to balance the need to generate greater product variability and versatility while keeping control over the overall solution. Through the Industrial IT certification process, ABB sought to instill control points to ensure reliability and compatibility while leveraging component developers' innovations and generating revenues from platform access. Although the strategy was never fully implemented, the new couplings offered by open, generic APIs to other systems in the Aspect Integrator architecture enabled $\mathrm{ABB}$ to cope with increased diversity and interdependencies arising from the Advant architecture. This opening up significantly increased variability in terms of diversity of third-party components and adaptiveness requirements toward OS, hardware, and other software changes. Also, acquired automation systems (e.g., Alfa Laval and Elsag Bailey) had to be incorporated around the millennium, and ABB's economic crisis necessitated cost reductions. The firm decided to reduce internal diversity and interdependencies by limiting the $800 \mathrm{xA}$ platform to run on Microsoft Windows OS. However, this move restricted ABB's control over decisions on product variability and compatibility, raising additional concerns:

Since we've moved away from making all products and systems, both $\mathrm{ABB}$ and the customers have ended up in a situation where we don't control the development of IT components. Hardware suppliers have their own life cycles, and Microsoft releases their updates and patches frequently .... We need to follow their development and customers need to follow both their [IT component suppliers] and ours. It's much more dynamic, in a way everything floats. (ABB Project manager)

For example, one platform user made a strategic decision to avoid all but essential updates after a substantial shutdown caused by the incompatibility between a new system version and firmware on a circuit board in an old machine. This increased diversity was considered an operational risk because automation system configurations had become highly dynamic and required constant updates (adaptiveness). 
Throughout the evolutionary process, distribution of decision rights extended the platform's functionality but also obliged $\mathrm{ABB}$ to repeatedly reconfigure the platform and operations to balance diversity and adaptiveness requirements. This became a significant driver in shifting organizing logic. Using digital design rules increased search spaces, expanded functional variability, and gave the platform provider access to new pools of agents and more extensive resource base. However, the mechanism reduced ABB's control over technological trajectories and rate of change as reprogrammability increased calls for adaptiveness. It also changed structural complexity by stimulating local diversity in products, which created new dependencies in local contexts (e.g., firmware in production environments).

The digitization of ABB's product platforms created hybrid cyber-physical systems with tensions arising from the difference in the evolutionary pace between digital and physical components. ABB had to carefully consider what adaptation strategies to deploy as a response to such tensions, that is, whether new digital capacities will remove the tension or generate new ones. This inertia has restrained ABB from establishing a full two-sided market and can be interpreted as an effect of system constraints embodied in CGPs that set requirements for change in system functions and their relations and conditions their use.

Increase in Stimulus-Response Variety: Digital components in ABB's platform vastly increased functional variety. Variety increase was founded on the ease of programming new functions and enhanced capacities for transmitting, processing, storing, and representing digital process data. Functional variety spurred environmental interactions, which became new sources of value creation and service provisioning. Each adaptation relieved specific concerns, but over time exposed the product platform to growing stimuli variety (in terms of sources and types). This was produced by increasingly open product boundaries and emergent interaction patterns. When increases in stimulus variety could not be efficiently tamed, more adaptations added new digital capacities with connectedness to new control levels that increased diversity. The increase in stimulus-response variety mechanisms refers to how digital components enrich and expand the scope of environmental interactions by increasing product functionality and the variety of stimuli related to it.

The stimulus-response variety mechanism played a significant role in scaling platform digitization. It expanded the set of agents interacting with the product, and such additions took place after each phase transition, except perhaps the last one (which intended to reduce stimuli variety). Expanded platform functionality increased connectedness toward new environments and generated distinct levels of diversity, adaptiveness, and mutual dependencies with emergent outcomes. These effects were mostly unforeseen and strengthened across phases, pushing the platform into new phase transitions. Between phases, such effects became increasingly important when introduced digital components enabled new types of interactions at higher organizational levels. For example, during the first phase, the proprietary design and inhouse component development limited stimuli variety. The configuration impeded ABB's ability to increase functional variety, which became a fundamental driver to transition to Advant architecture. The effects of stimuli variety were more profound for the Aspect Integrator, where technologically distinct potential for connectivity dimensions became an important driver of firm-wide radical change. Advant's new digital components enabled integration across previously separate engineering systems, but these interactions created additional dependencies. ABB had to invent new ways of increasing its adaptiveness toward updates in external vendors' systems. The response introduced another platform layer with new digital components and APIs, boosting the scope and number of information-based couplings and further increasing stimulus-response variety:

Realizing that everybody needs an integration platform, we started thinking about business models for our platform. We can sell it to Siemens [main competitor]. We need to be open and offer this to everybody, not just automation. We had discussions with arms makers, construction companies. We formed alliances with Microsoft, Intel, Accenture. In addition to using it for internal components, we wanted to certify external components with business models based on licensing. Then the IT bubble burst and $\mathrm{ABB}$ had a financial crisis ... so it was back to basics. (ABB R\&D manager)

Similarly, introducing open APIs and communication standards and building on Microsoft technology in the 800xA reduced system fragmentation, decreased the number of platform versions, and enabled new types of component-level innovation. These changes increased the rate of adaptation to the external environment and triggered an inflow of innovation. But they also increased maintenance requirements by pushing customers toward dynamic software maintenance and frequent upgrades, which raised operational risk. Thus, the transition from the Aspect Integrator to the 800xA did not necessarily expose the product platform to new environments, but it changed the nature of interactions due to new types of dependencies. Most resources had to be devoted to coevolving the platform with changes in the digital environment to maintain compatibility with the physical production: 
The main part of development costs is devoted to maintaining the architecture ... these systems are so complex. I'm not sure about the exact number but I know that a couple of years ago we had ten million lines of code in the platform. (ABB Engineer)

Increases in stimuli-response variety generate self-reinforcing cycles of change that alter the complexity in the system's agents and elements and influence the platform's ability to tame it. As reflected in the case, connectedness toward new environments altered diversity, adaptiveness, and mutual dependencies. This resulted from continued scaling of digital components in the platform, as digitization provided flexible means to extend the platform's functional scope. In each cycle, further digitization increased variety in system functions to respond effectively to reverse salient and related tensions. Over time, the increased functional variety created new spaces for novel environmental interactions, leading to further amplification of the variety of stimuli and calling for further digitization.

The evolutionary pattern in ABB's product platform suggests that substantial architectural change that expands platform scope will trigger transitions in the organizing logic when the new type of stimuli call for significant shifts in the agent's schemata, connections, and mutual dependencies. However, when negative firm-level and environmental feedback is present, agents will selectively engage in architectural change to lower the stimuli variety by curbing environmental interactions (e.g., reducing numbers of supported OS and targeted markets). Thus, stimuli-response variety configurations can and should be orchestrated by platform providers. However, outcomes of digitally induced platform change are not easily foreseen because they are mediated by emergent and often unintended change in CGPs, which generate emergent system-level outcomes. Table 4 summarizes how the introduction of digital capacities produced these effects and triggered phase transitions over time.

\section{Implications and Conclusions}

Distinct platform types have been viewed as evolutionary stages (Gawer 2009, 2014), and previous studies suggest that digitization triggers such evolutionary transitions toward ecosystem-based organizing logics (Svahn et al. 2017; Yoo et al. 2010). However, we know little about how digitization drives such platform transitions and what mechanisms make them more likely or necessary. At ABB, waves of digitization were followed by significant organizational outcomes as they changed the boundaries of the platform scope, scale, and its sources of value creation and extraction (Bharadwaj et al. 2013; Nambisan et al. 2017). These were enabled by the traits and design rules of the digital artifacts (Kallinikos et al. 2013; Lyytinen et al. 2016). The resultant blurring of boundaries through the infusion of digital capacities pushed the incumbent firm to gradually transition to platform ecosystems (Thomas et al. 2014; Yoo et al. 2010). Our analysis reveals three mechanisms modeled as CGPs that triggered such transitions.

\section{Research Implications}

Prior studies have shown that digitization expands product scale and scope and change the organizing logic of its hosting firm (Lee and Berente 2012; Svahn et al. 2017). However, there is a paucity of studies of mechanisms that undergird deep cumulative changes in the firm's organizing logic. To address this gap, we built on CAS theory and synthesized the role of interactions during emergence (CGPs) (Holland 1998; Page 2010), digitization (Kallinikos et al. 2013; Yoo et al. 2010), and platform evolution (Constantinides et al. 2018; de Reuver et al. 2017; Gawer 2014) into a conceptual scaffolding that allowed us to trace the cumulative effects of waves of digitization on ABB's automation platform and ensuing shifts in the firm's organizing logic. We identified three endogenous CGPs and related networks of mechanisms - interaction rules, design control, and stimuliresponse variety - through which digitization triggered product platform transitions and shaped new organizing logics. These mechanisms offer an analytical apparatus for future studies of how digitization unfolds in platform transitions. Whereas the initial typology by Gawer (2014) identifies essential distinctions among technological platforms, the variations in platform types we identified and their multifinality as complex adaptive systems suggest that a more fine-grained classification of (digital) platform types is essential for advancing understanding of digitization's impact on product platforms.

Outcomes of the three mechanisms are not deterministic. They have highly interactive composite effects, although they were not examined in detail in this study (Henfridsson and Bygstad 2013). The mechanisms also show that macro-level change affects interactions at the micro-level, which, in turn, produces emergent macro-level orders (Hedström and Swedberg 1998). Thus, a new organizing logic emerges from myriad interactions enabled and enforced by the three digital (CGPs) mechanisms and other (nondigital) mechanisms (CGPs) (Holland 1998). These mechanisms have fractal properties in that they operate at multiple levels simultaneously with large variations in their scope and intensity. As a product platform accrues digital capacities, process outcomes cannot be understood solely by analyzing static configurations of its social and technical elements (Tanriverdi et al. 2010; 
Table 4. Characteristics of Phase Transitions

\begin{tabular}{|c|c|c|c|}
\hline Construct & Transition 1 & Transition 2 & Transition 3 \\
\hline $\begin{array}{l}\text { Reverse } \\
\text { salient }\end{array}$ & $\begin{array}{l}\text { Proprietary components and inter- } \\
\text { faces, and tight data service } \\
\text { coupling hinder logical engineering } \\
\text { solutions' reuse, performance of } \\
\text { general-purpose digital components } \\
\text { and integration. }\end{array}$ & $\begin{array}{l}\text { Growing mutual dependencies from } \\
\text { tight coupling to external components, } \\
\text { while requirements grow for further } \\
\text { integration of internal and external } \\
\text { business processes. }\end{array}$ & $\begin{array}{l}\text { Trade-offs in resource consumption } \\
\text { associated with ensuring compatibility } \\
\text { across OSs and increased functionality in } \\
\text { use environments. }\end{array}$ \\
\hline $\begin{array}{l}\text { Salient } \\
\text { digital } \\
\text { capacities } \\
\text { introduced }\end{array}$ & $\begin{array}{l}\text { Object-oriented architecture, open } \\
\text { standards, shared database, and } \\
\text { general-purpose components (OS, } \\
\text { hardware) in manufacturing zone } \\
\text { (PRM levels } 2 \text { "Area supervisory } \\
\text { control" and } 3 \text { "Site manufacturing } \\
\text { operations and control"). }\end{array}$ & $\begin{array}{l}\text { Object architecture with APIs, } \\
\text { adaptation module, and component } \\
\text { certification. }\end{array}$ & $\begin{array}{l}\text { Standardization on Windows OS and } \\
\text { increased use of COTS and } \\
\text { communication/service standards. }\end{array}$ \\
\hline $\begin{array}{l}\text { Change in } \\
\text { interaction } \\
\text { rules }\end{array}$ & $\begin{array}{l}\text { Decoupling of data and service } \\
\text { gives combinatorial options for } \\
\text { software and data use increasing } \\
\text { connectedness among software } \\
\text { components. }\end{array}$ & $\begin{array}{l}\text { Loose couplings toward external soft- } \\
\text { ware services reduce mutual depen- } \\
\text { dencies and drive connectedness by } \\
\text { allowing data to be combined from } \\
\text { external sources and accessed from } \\
\text { the enterprise zone with little effort. }\end{array}$ & $\begin{array}{l}\text { Support for communication standards } \\
\text { increases connectedness across produc- } \\
\text { tion components and production sites, and } \\
\text { toward business processes at the enter- } \\
\text { prise zone (PRM levels } 4 \text { "Site business } \\
\text { planning" and } 5 \text { "Enterprise network"). }\end{array}$ \\
\hline $\begin{array}{l}\text { Distribution } \\
\text { of design } \\
\text { control }\end{array}$ & $\begin{array}{l}\text { Couplings to external software } \\
\text { components interacting with PRM } \\
\text { level } 3 \text { ("Site manufacturing } \\
\text { operations and control") increase } \\
\text { interdependencies and } \\
\text { adaptiveness requirements. }\end{array}$ & $\begin{array}{l}\text { New interfaces and support for } \\
\text { standards increase internal and } \\
\text { environmental connectedness, and } \\
\text { diversity and adaptiveness toward } \\
\text { the IT industry solutions and busi- } \\
\text { ness environments. } \\
\text { - Distribution of decision rights to the } \\
\text { IT industry environment. } \\
\text { - Certification scheme to reconfigure } \\
\text { decision rights. }\end{array}$ & $\begin{array}{l}\text { Higher reliance on COTS and support } \\
\text { for standards increase diversity and } \\
\text { adaptiveness requirements by distrib- } \\
\text { uting decision rights to external actors. } \\
\text { To ensure security and compatibility } \\
\text { among diverse and adaptive connected } \\
\text { components, ABB strengthens input } \\
\text { control through testing and requirements } \\
\text { for updated software. }\end{array}$ \\
\hline $\begin{array}{l}\text { Change in } \\
\text { stimuli- } \\
\text { response } \\
\text { variety }\end{array}$ & $\begin{array}{l}\text { Increased connectedness and } \\
\text { mutual dependencies toward } \\
\text { external software components } \\
\text { expose the product platform to } \\
\text { stimuli from the IT industry. }\end{array}$ & $\begin{array}{l}\text { Functionality to integrate data } \\
\text { sources Increase connectedness to } \\
\text { business environments and elimin- } \\
\text { ates the anchoring in process auto- } \\
\text { mation, increasing both internal } \\
\text { (e.g., the Industrial IT certification } \\
\text { program) and external (e.g., across } \\
\text { technologies and industries) stimuli } \\
\text { (increase interdependencies, diver- } \\
\text { sity, and requirements for adap- } \\
\text { tiveness). } \\
\text { Platform functionality for wide } \\
\text { range of OSs and acquired control } \\
\text { systems. }\end{array}$ & $\begin{array}{l}\text { Decreased scope of use environments } \\
\text { lowers environmental stimuli. Simul- } \\
\text { taneous increased reliance on COTS, } \\
\text { general-purpose standards, and con- } \\
\text { nectedness through the internet signi- } \\
\text { ficantly increase stimuli (diversity and } \\
\text { adaptiveness requirement) from the IT } \\
\text { environment. }\end{array}$ \\
\hline $\begin{array}{l}\text { Change in } \\
\text { organizing } \\
\text { logic }\end{array}$ & $\begin{array}{l}\text { From internal product-centric con- } \\
\text { trol over design and manufacturing } \\
\text { to coping with dependences in } \\
\text { physical production environment } \\
\text { into specializing in process auto- } \\
\text { mation functionality and integrating } \\
\text { external competencies and } \\
\text { components. }\end{array}$ & $\begin{array}{l}\text { Product platform governance } \\
\text { structures to coordinate distributed } \\
\text { set of agents and diverse techno- } \\
\text { logical components through } \\
\text { integrative capacity and compati- } \\
\text { bility verification. } \\
\text { - Identity challenged by a transfor- } \\
\text { mation of business portfolio toward } \\
\text { high-return business enabled by } \\
\text { Industrial IT architecture, and } \\
\text { realigning operations along } \\
\text { customer segments. }\end{array}$ & $\begin{array}{l}\text { Product platform with high degree of } \\
\text { internal design and manufacturing for } \\
\text { production process components while } \\
\text { leveraging communication standards to } \\
\text { integrate data across the enterprise and } \\
\text { innovative capabilities within the } \\
\text { environment. } \\
\text { - The product platform viewed as } \\
\text { dedicated to process automation. } \\
\text { Organizational restructuring from } \\
\text { customer segments into process } \\
\text { automation business. }\end{array}$ \\
\hline
\end{tabular}


Yoo et al. 2012; Yoo et al. 2010). Order emerges performatively from micro-level phenomena during platform design and use. For example, at ABB initially narrow digitization effort eventually led to unexpected and unintended changes that transitioned the product platform toward a platform ecosystem. Across and within each phase, the change was subject to "increasing returns," that is, capabilities previously assimilated within the system could be leveraged later and were necessary to enter the next stage (Kurzweil 2004). Digitization eventually changed from handling direct information about the physical process to dedicated sets of information functions and services to coordinating production processes and full process systems. Ultimately, this generated new kinds of relationships and interactions among external partners in areas where ABB had insufficient knowledge and skills or could now leverage economies of scale or scope. Initial digitization in the device and network layers enabled to progress to loosely coupled services and content, causing CGPs to generate substantial platform complexity. Consequently, in later stages digitization covered substantial parts of ABB's and its customers' operations (with more significant and broader effects) and involved multiple subsystems simultaneously. This sequencing provides insights into how digitization processes are likely to unfold in product platforms and also suggests the need for future research on their path dependencies.

\section{Practical Implications}

Our study has a several practical implications. First, it underscores that digitization expands the scope of product platforms in terms of both functions and participating agents. The consequent increases in diversity, adaptiveness, connectedness, and dependencies drives complexity and generates effects that are difficult (or impossible) to predict. Seemingly innocuous digitization can have strategically significant effects, which calls for strategic heedfulness to digital technology design and its role in orchestrating internal and external relations and interactions. Leveraging integrative capacity of digital technology calls for continuously tuning interactions and dynamically reconfiguring technical and organizational resources. Second, digitization can give architectural leverage in terms of production, innovation, and transactions (Thomas et al. 2014). Our research suggests that such processes can be stimulated in sequences - at ABB we observed changes in production, then innovation, and finally, to some degree, transactions. Managers should consider the kind of leverage they seek through digitization and review sequences and path dependencies for achieving it while recognizing that unpredictable changes may be unleashed. For high-reliability settings, such analysis should consider security and avoid pursuing (for example) transaction lever- age through multisided markets, if reliability in the local context cannot be guaranteed. Third, our study shows that the idea of a reverse salient can serve as a valuable point of departure for an organizational transition. Platform providers should consider not only immediate resolution but also how responses can be used as strategic pivots. Fourth, while digital capacities enable firms to expand target markets radically, such growth needs to be aligned with organizational capacity and current platform use. If these cannot be reasonably aligned, providers should consider exploring expansion options separately. Finally, pace and patterns of change strongly differ in physical and digital architecture. Our findings suggest that managing these differences through, for example, appropriate control points is essential for successfully digitizing product platforms.

Three limitations of this study should be noted. First, we focused on an industry that is highly dependent on very reliable machinery with long life cycles. The differences in dynamics between the digital and physical architectures (and hence some of the identified adaptive tensions) are pronounced in the focal context. It would be beneficial to examine the digitization of other types of platforms. Second, we examined platform evolution in a world-leading firm in a capital-intensive high-tech engineering industry. Processes and consequences of physical environments' digitization may vary substantially in other contexts. Future studies should investigate the dynamics of product platforms with different resource bases. Third, industrial control systems are used in numerous sectors, and innovation adoption patterns might be different across use contexts. For example, most platform users we studied operate in industries that have been highly profitable in recent decades. Platforms in more costdependent industries might be subject to other dynamics.

To conclude, our study provides novel empirically grounded insights on the role of digitization in product platform transitions by empirically demonstrating the multilevel and recursive nature of digitally driven growth in product platforms. We hope that this work will stimulate future research to identify additional complex patterns and mechanisms to advance richer theorizing of the impact of digitization on platform transitions.

\section{Acknowledgments}

The authors wish to thank seminar participants at Case Western Reserve University, University of Georgia, and University of Texas at Austin for their valuable feedback. We are also grateful to the senior editors and the review team for their constructive feedback, thoughtful guidance, and support. This research is supported by the Marianne and Marcus Wallenberg Foundation. 


\section{References}

ABB. 2000. ABB Group Annual Report 1999, ABB Ltd., Zurich (retrieved from https://library.e.abb.com/public/ 3a011e9ef019f666c1256cb60030d421/ABB\%20Group\%20 Financial\%20Review,\%201999_English.pdf?x-sign=A501z Ozpa5p7iN0iCxWTHLAesM5o4YDZ8q7xz7XtGc/oHkC0 ejem7WSrcwz+ZxJt).

ABB. 2001. 2000 Annual Report of $A B B$ as filed with the United States Securities and Exchagne Commission, form 20-F (retrieved from https://www.sec.gov/Archives/edgar/containers/ fix044/1091587/0000912057-01-506820.txt).

ABB 2003. 2002 Annual Report of ABB as filed with the United States Securities and Exchagne Commission, form 20-F (retrieved from https://www.sec.gov/Archives/edgar/data/ 1091587/000104746903022874/a2110845z20-f.txt).

$A B B$ Review. 2001. "Industrial IT and Collaborative Commerce: Accelerating Next-Generation eMarketplaces," ABB Review, eTechnology Section, pp. 20-22 (retrieved from https://library.e.abb.com/public/44f57473ba33916ec1256ddd0 0346e39/20-22\%20M684.pdf).

Anderson, P. 1999. "Perspective: Complexity Theory and Organization Science," Organization Science (10:3), pp. 216-232.

Benbya, H., and McKelvey, B. 2006. "Toward a Complexity Theory of Information Systems Development," Information Technology \& People (19:1), pp. 12-34.

Bharadwaj, A., El Sawy, O. A., Pavlou, P. A., and Venkatraman, N. 2013. "Digital Business Strategy: Toward a Next Generation of Insights," MIS Quarterly (37:2), pp. 471-482.

Bowen, G. A. 2006. "Grounded Theory and Sensitizing Concepts," International Journal of Qualitative Methods (5:3), pp. 12-23.

Bresnahan, T. F., and Greenstein, S. 1999. "Technological Competition and the Structure of the Computer Industry," Journal of Industrial Economics (47:1), pp. 1-40.

Charmaz, K. 2006. Constructing Grounded Theory: A Practical Guide through Qualitative Analysis, Thousand Oaks, CA: SAGE Publications.

Constantinides, P., Henfridsson, O., and Parker, G. G. 2018. "Introduction-Platforms and Infrastructures in the Digital Age," Information Systems Research (29:2), pp. 381-400.

Cusumano, M. A., Mylonadis, Y., and Rosenbloom, R. S. 1992. "Strategic Maneuvering and Mass-Market Dynamics: The Triumph of VHS over Beta," Business History Review (66:1), pp. 51-94.

de Reuver, M., Sørensen, C., and Basole, R. C. 2017. "The Digital Platform: A Research Agenda," Journal of Information Technology (33:2), pp. 1-12.

Eaton, B., Elaluf-Calderwood, S., Sørensen, C., and Yoo, Y. 2015. "Distributed Tuning of Boundary Resources: The Case of Apple's iOS Service System," MIS Quarterly (39:1), pp. 217-244.

Eisenhardt, K. 1989. "Building Theories from Case Study Research," Academy of Management Review (14:4), pp. 532-550.

Gawer, A. 2009. Platforms, Markets and Innovation, Cheltenham, UK: Edward Elgar Publishing.

Gawer, A. 2014. "Bridging Differing Perspectives on Technological Platforms: Toward an Integrative Framework," Research Policy (43:7), pp. 1239-1249.
Gawer, A., and Cusumano, M. A. 2014. "Industry Platforms and Ecosystem Innovation," Journal of Product Innovation Management (31:3), pp. 417-433.

Goldstein, J. 1999. "Emergence as a Construct: History and Issues," Emergence (1:1), pp. 49-72.

Hedström, P., and Swedberg, R. 1998. "Social Mechanisms: An Introductory Essay," in Social Mechanisms: An Analytical Approach to Social Theory, P. Hedström and R. Swedberg (eds.), Cambridge, UK: Cambridge University Press, pp. 1-31.

Henfridsson, O., and Bygstad, B. 2013. "The Generative Mechanisms of Digital Infrastructure Evolution," MIS Quarterly (37:3), pp. 907-931.

Henfridsson, O., and Yoo, Y. 2014. "The Liminality of Trajectory Shifts in Institutional Entrepreneurship," Organization Science (25:3), pp. 932-950.

Holland, J. H. 1998. Emergence: From Chaos to Order, Reading, MA: Perseus.

Hughes, T. P. 1983. Networks of Power: Electrification in Western Society, 1880-1930, Baltimore: Johns Hopkins University Press.

Kallinikos, J., Aaltonen, A., and Marton, A. 2013. "The Ambivalent Ontology of Digital Artifacts," MIS Quarterly (37:2), pp. 357-370.

Karhu, K., Gustafsson, R., and Lyytinen, K. 2018. "Exploiting and Defending Open Digital Platforms with Boundary Resources: Android's Five Platform Forks," Information Systems Research (29:2), pp. 479-497.

Kretschmer, T., and Claussen, J. 2016. "Generational Transitions in Platform Markets-The Role of Backward Compatibility," Strategy Science (1:2), pp. 90-104.

Kurzweil, R. 2004. "The Law of Accelerating Returns," in Alan Turing: Life and Legacy of a Great Thinker, C. Teuscher (ed.), Berlin: Springer, pp. 381-416.

Lamberson, P., and Page, S. E. 2012. “Tipping Points,” Quarterly Journal of Political Science (7:2), pp. 175-208.

Langley, A. 1999. "Strategies for Theorizing from Process Data," Academy of Management Review (24:4), pp. 691-710.

Lee, J., and Berente, N. 2012. "Digital Innovation and the Division of Innovative Labor: Digital Controls in the Automotive Industry," Organization Science (23:5), pp. 1428-1447.

Lusch, R. F., and Nambisan, S. 2015. "Service Innovation: A Service-Dominant Logic Perspective," MIS Quarterly (39:1), pp. 155-175.

Lyytinen, K., Yoo, Y., and Boland Jr., R. J. 2016. "Digital Product Innovation Within Four Classes of Innovation Networks," Information Systems Journal (26:1), pp. 47-75.

McIntyre, D. P., and Srinivasan, A. 2017. "Networks, Platforms, and Strategy: Emerging Views and Next Steps," Strategic Management Journal (38:1), pp. 141-160.

Meyer, M. H., and Lehnerd, A. P. 1997. The Power of Product Platforms, New York: Free Press.

Miles, M. B., and Huberman, A. M. 1994. Qualitative Data Analysis: An Expanded Sourcebook, Thousand Oaks, CA: SAGE Publications.

Morel, B., and Ramanujam, R. 1999. "Through the Looking Glass of Complexity: The Dynamics of Organizations as Adaptive and Evolving Systems," Organization Science (10:3), pp. 278-293.

Nambisan, S., Lyytinen, K., Majchrzak, A., and Song, M. 2017. "Digital Innovation Management: Reinventing Innovation 
Management Research in a Digital World," MIS Quarterly (41:1), pp. 223-238.

Nicolis, G., and Prigogine, I. 1989. Exploring Complexity, New York: Freeman.

Page, S. E. 2010. Diversity and Complexity, Princeton, NJ: Princeton University Press.

Parker, G., and Van Alstyne, M. 2018. "Innovation, Openness, and Platform Control," Management Science (64:7), pp. 3015-3032.

Parker, G., Van Alstyne, M., and Jiang, X. 2017. "Platform Ecosystems: How Developers Invert the Firm," MIS Quarterly (41:1), pp. 255-254.

Patton, M. Q. 1990. Qualitative Evaluation and Research Methods, Newbury Park, CA: SAGE Publications.

Robertson, D., and Ulrich, K. 1998. "Planning for Product Platforms," Sloan Management Review (39:4), pp. 19-31.

Rosenberg, N. 1969. "The Direction of Technological Change: Inducement Mechanisms and Focusing Devices," Economic Development and Cultural Change (18:1), pp. 1-24.

Sambamurthy, V., and Zmud, R. 2000. "Research Commentary: The Organizing Logic for an Enterprise's IT Activities in the Digital Era-A Prognosis of Practice and a Call for Research," Information Systems Research (11:2), pp. 105-114.

Simon, H. A. 1962. "The Architecture of Complexity," Proceedings of the American Philosophical Society (106:6), pp. 467-482.

Simpson, T. W. 2004. "Product Platform Design and Customization: Status and Promise," Artificial Intelligence for Engineering Design, Analysis and Manufacturing (18:1), pp. 3-20.

Svahn, F., Mathiassen, L., and Lindgren, R. 2017. "Embracing Digital Innovation in Incumbent Firms: How Volvo Cars Managed Competing Concerns," MIS Quarterly (41:1), pp. 239-254.

Tanriverdi, H., and Lim, S.-Y. 2017. "How to Survive and Thrive in Complex, Hypercompetitive, and Disruptive Ecosystems? The Roles of IS-Enabled Capabilities," in Proceedings of the $38^{\text {th }}$ International Conference on Information Systems, Seoul.

Tanriverdi, H., Rai, A., and Venkatraman, N. 2010. "Research Commentary-Reframing the Dominant Quests of Information Systems Strategy Research for Complex Adaptive Business Systems," Information Systems Research (21:4), pp. 822-834.

Thomas, L. D., Autio, E., and Gann, D. M. 2014. "Architectural Leverage: Putting Platforms in Context," Academy of Management Perspectives (28:2), pp. 198-219.

Tiwana, A., Konsynski, B., and Bush, A. 2010. "Platform Evolution: Coevolution of Platform Architecture, Governance and Environmental Dynamics," Information Systems Research (21:4), pp. 675-687.

Van de Ven, A. H. 1992. "Suggestions for Studying Strategy Process: A Research Note," Strategic Management Journal (13:S1), pp. 169-188.
Wheelwright, S. C., and Clark, K. B. 1992. Revolutionizing Product Development: Quantum Leaps in Speed, Efficiency, and Quality, New York: Simon and Schuster.

Yoo, Y., Boland, R. J., Lyytinen, K., and Majchrzak, A. 2012. "Organizing for Innovation in the Digitized World," Organization Science (23:5), pp. 1398-1408.

Yoo, Y., Henfridsson, O., and Lyytinen, K. 2010. "Research Commentary: The New Organizing Logic of Digital Innovation: An Agenda for Information Systems Research," Information Systems Research (21:4), pp. 724-735.

\section{About the Authors}

Johan Sandberg is an associate professor at the Swedish Center for Digital Innovation at the Department of Informatics, Umeå University. His research interests relate to the transformative effects of digital innovation on organizing. His research has been published in journals such as Journal of the Association for Information Systems, European Journal of Innovation Management, and Business \& Information Systems Engineering.

Jonny Holmström is a professor at the Swedish Center for Digital Innovation at the Department of Informatics, Umeå University. He is the director and co-founder of Swedish Center for Digital Innovation and writes, consults, and speaks on topics such as digital innovation, digital transformation, and digital entrepreneurship. His work has appeared in journals such as Communications of the AIS, Design Issues, European Journal of Information Systems, Information and Organization, Information Systems Journal, Information Technology and People, Journal of the AIS, Journal of Information Technology, Journal of Strategic Information Systems, Research Policy, and The Information Society.

Kalle Lyytinen (Ph.D., Computer Science, University of Jyväskylä; Dr. h.c. Umeå University, Copenhagen Business School, Lappeenranta University of Technology) is Distinguished University Professor and Iris S. Wolstein Professor of Management Design at Case Western Reserve University, and a distinguished visiting professor at Aalto University, Finland. He is among the top five IS scholars in terms of his h-index (85); he is a LEO Award recipient (2013), AIS Fellow (2004), and the former chair of IFIP WG 8.2 "Information Systems and Organizations." He has published more than 400 refereed articles and edited or written over 30 books or special issues. He conducts primarily research on digital innovation and transformation, design work, requirements in large systems, and the emergence of digital infrastructures. 


\section{Appendix A}

\section{Data Collection}

We collected data in two periods (2007-2010 and 2011-2017) through interviews, participant observation, and inspection of both internal and publicly available archival data. Indications of the transformations triggered by digitization emerged during our study that prompted an exploratory case study (Eisenhardt 1989; Yin 2003) of ABB's control system evolution. The first data collection period involved field observations at five sites (three ABB offices and two mining plants) and 14 interviews (10 with ABB staff with positions including sales manager, mining automation unit manager, project manager, and process engineer, and four with informants from a large mining company: a site IT manager, site maintenance manager, and two technicians. We collected extensive documentation, such as product specifications, market analyses, project reports, and descriptions of installations at user sites.

During the second data collection period, we followed a project aimed at identifying ways of increasing certified solutions from third-party developers to offer new functions for ABB's 800xA process automation product. This period included nine interviews with third-party developers and representatives of process industries (pulp and mining companies), participation in meetings and workshops, and collection of documents (both ABB internal reports and public documents). We attended several project meetings and workshops on lessons from historical design decisions and the concept's development, including three days of training on development and integration. Finally, we gathered substantial amounts of both internal and external archival data such as ABB's annual reports, technical specifications for each product release, related market analyses, and product pamphlets.

In each interview, we asked semi-structured open-ended questions (Spradley 1979) about informants' roles and responsibilities, the product platform's history and status, and the informants' interactions with it. We recorded and transcribed each interview, which lasted on average an hour (with significant variance upward), compiled researchers' notes of meetings and workshops, and verified transcripts' correctness with the interviewees.

\section{References}

Eisenhardt, K. 1989. "Building Theories from Case Study Research,” Academy of Management Review,(14:4), pp. 532-550. Spradley, J. P. 1979. The Ethnographic Interview, New York: Holt, Rinehart and Winston.

Yin, R. K. 2003. Case Study Research: Design and Methods ( $3^{\text {rd }}$ ed.), Thousand Oaks: SAGE Publications. 


\section{Appendix B}

\section{Coding Extracts}

\begin{tabular}{|c|c|c|}
\hline Construct & Dimension & Illustrative Examples from the Data \\
\hline \multirow{4}{*}{ 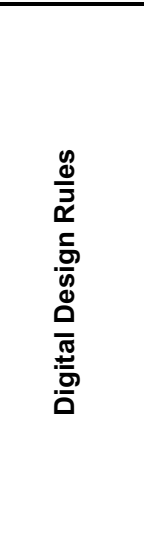 } & Reprogrammability & $\begin{array}{l}\text { "It provided a low-level interface in C and C++ and ran on HPUX. Since then, OMF has been used } \\
\text { in Advant OCS and MES as the communication middleware. Several thousand Advant OCS have } \\
\text { been sold in recent years. In } 1993 \text { and } 1994 \text { the focus was on performance and stability } \\
\text { improvements. In } 1995 \text { the first application frameworks (C++, Python) were developed and a port } \\
\text { to OpenVMS was made for a customer. } 1996 \text { was the year when the Smalltalk framework was } \\
\text { finished and a port to Digital Unix was introduced." }\end{array}$ \\
\hline & Data homogenization & $\begin{array}{l}\text { "OMF makes process and production data available to the majority of computer programmers } \\
\text { and users, even those not necessarily involved in the industrial control field. For instance, it is } \\
\text { easy to develop applications in Microsoft Word, Excel, and Access to access process information." }\end{array}$ \\
\hline & Decoupling & $\begin{array}{l}\text { "One major problem OMF had to solve was the support for heterogeneous environments } \\
\text { (platforms, languages, communication protocols, field busses etc.). At this time it was recognized } \\
\text { that the commitment to a full object-oriented approach promised the biggest advantages with } \\
\text { regard to modularity, extendibility, portability and interoperability." }\end{array}$ \\
\hline & Distributedness & $\begin{array}{l}\text { "We wanted to create a common engineering environment where information was shared, so we } \\
\text { created a large database in Oracle that the different applications could interact with." }\end{array}$ \\
\hline \multirow{4}{*}{ 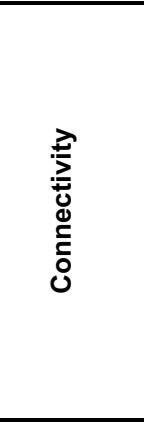 } & Connectedness & $\begin{array}{l}\text { "Our control system builder can work toward the data base, CAD for electricity, piping and } \\
\text { instrument diagrams. Then you can start re-using libraries etc." }\end{array}$ \\
\hline & Diversity & $\begin{array}{l}\text { "Products such as programmable control systems use sophisticated sensor technology to } \\
\text { monitor, regulate and optimize a wide variety of technical and environmental control } \\
\text { processes in factories, shipyards, theatres and even private homes." }\end{array}$ \\
\hline & Adaptiveness & $\begin{array}{l}\text { "The system is now developed further using components based on new, standard technologies. } \\
\text { During this development, further new components become available on the market. ABB faced } \\
\text { this issue more than once." }\end{array}$ \\
\hline & Mutual dependencies & $\begin{array}{l}\text { "A typical example of such an incompatible change, is a change in the communication protocol } \\
\text { between OMF clients and servers. All versions of OMF must be able to talk to each other to make } \\
\text { the system flexible and open" }\end{array}$ \\
\hline \multirow{3}{*}{ 号 } & Interaction rules & $\begin{array}{l}\text { "Advant OCS can be configured in a multitude of ways, depending on the size and complexity } \\
\text { of the process. The initial investment can consist of stand-alone process controllers and, } \\
\text { optionally, local operator stations for control and supervision of separate machines and process } \\
\text { sections. Subsequently, several process controllers can be interconnected and, together with } \\
\text { central operator and information management stations, build up a control network. Several control } \\
\text { networks can be interconnected to give a complete plant network which can share centrally } \\
\text { located operator, information and engineering workplaces." }\end{array}$ \\
\hline & Design control & $\begin{array}{l}\text { "A couple of years after we released Advant we ran into trouble. The system integrated data, but } \\
\text { we couldn't get other actors to change their data format, which meant that we had to assume } \\
\text { responsibility for data storage for a lot of external systems .... we wanted to develop the } \\
\text { functionality, but in doing so we assumed responsibility for developing other actors' } \\
\text { components. We realized pretty soon that it wasn't sustainable." }\end{array}$ \\
\hline & $\begin{array}{l}\text { Stimuli-response } \\
\text { variety }\end{array}$ & $\begin{array}{l}\text { "But even for a big company like ABB, with more than } 220,000 \text { employees, the time for proprietary } \\
\text { solutions expires. Indeed only functionality, which is not applicable as COTS (components off } \\
\text { the shelf) will be developed and maintained by ABB in the future." }\end{array}$ \\
\hline
\end{tabular}

Note: The highlighted text (bold italics) exemplifies passages from the data that served as basis for the coding. 
Table B2. Phase Transition 2

\begin{tabular}{|c|c|c|}
\hline Construct & Dimension & Illustrative Examples from the Data \\
\hline \multirow{4}{*}{ 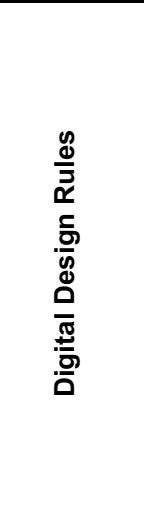 } & Reprogrammability & $\begin{array}{l}\text { "All functionality was then realized as aspect systems. We built aspect systems, graphical } \\
\text { builders, graphical presentations, history modules, trend modules, reporting modules, control } \\
\text { builders, all functionality in the control system was integrated through this platform." }\end{array}$ \\
\hline & Data homogenization & $\begin{array}{l}\text { "We intend to achieve this common architecture by using software to link our various technical } \\
\text { platforms together and by improving compatibility in succeeding generations of each of our } \\
\text { products and systems." }\end{array}$ \\
\hline & Decoupling & $\begin{array}{l}\text { "So we developed APIs for our system and an adaptation module that could hook into APIs in } \\
\text { other systems." }\end{array}$ \\
\hline & Distributedness & $\begin{array}{l}\text { "In an inventory in } 2000, \text { we went through all the customers' systems and created our own } \\
\text { database, which was great for a year or so. Then the customers started replacing parts, or } \\
\text { maybe some consultant or some other company did. Then the information we created was } \\
\text { basically useless. This kind of information is great, but updating procedures must be more or less } \\
\text { fully automatic. Every little thing has some kind of intelligence, everything with a plug has } \\
\text { firmware." }\end{array}$ \\
\hline \multirow{4}{*}{ 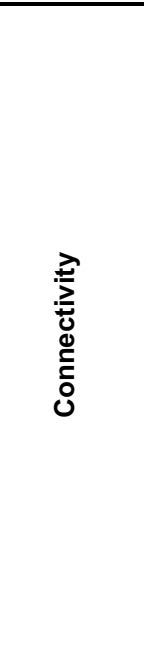 } & Connectedness & $\begin{array}{l}\text { "We also intend to expand our Industrial IT offering. This means, in addition to creating a single } \\
\text { Industrial IT architecture as discussed above, we will increasingly emphasize products and } \\
\text { systems that can link our business processes with those of our customers." }\end{array}$ \\
\hline & Diversity & $\begin{array}{l}\text { "At about this time we started thinking that this idea of holding information together was interesting } \\
\text { for a lot of actors, not only engineers. It's interesting for operators, maintenance staff, production } \\
\text { managers etc. ... and then we started to think about the next generation of control systems. The } \\
\text { basic architectural philosophy emerged during these years; at first we thought we were developing } \\
\text { an integration platform for engineering tools, then for connecting all the different parts of the } \\
\text { control system, then to integrate different products and units in ABB, and eventually to integrate } \\
\text { the whole world." } \\
\text { "We had discussions with large construction companies, weapons manufacturers. We formed } \\
\text { alliances with Microsoft, Intel and Accenture. In addition to using it for internal components, we } \\
\text { wanted to certify external components with business models based on licensing." }\end{array}$ \\
\hline & Adaptiveness & $\begin{array}{l}\text { "All functionality was then realized as aspect systems. We built aspect systems, graphical } \\
\text { builders, graphical presentations, history modules, trend modules, reporting modules, control } \\
\text { builders, all functionality in the control system was integrated through this platform." }\end{array}$ \\
\hline & Mutual dependencies & $\begin{array}{l}\text { "... developing a common architecture across the range of our products and systems so that they } \\
\text { can be easily combined with each other and with our customers' systems." }\end{array}$ \\
\hline \multirow{3}{*}{ 过 } & Interaction rules & $\begin{array}{l}\text { "So we developed APIs for our system and an adaptation module that could hook into APIs in } \\
\text { other systems. Then we didn't have to care, applications could store data wherever they wanted, } \\
\text { we just made sure we could access the data they produced through the APIs they published." }\end{array}$ \\
\hline & Design control & $\begin{array}{l}\text { "Then the idea was, OK, we have this platform for our control system. That is an architecture and } \\
\text { integration platform aimed at internal use. Why don't we also use it externally? Systems, } \\
\text { products, components, the idea was that you should be able to certify everything. We realized } \\
\text { that this was an extremely good concept and that we could start certifying external products too. } \\
\text { We could start certifying the PCs that we build our system on, network components, routers, } \\
\text { gateways, switches, stuff like that. We can certify software that is to be connected." }\end{array}$ \\
\hline & $\begin{array}{l}\text { Stimuli-response } \\
\text { variety }\end{array}$ & $\begin{array}{l}\text { "It turned into a competition in ABB about who had most certified products. This is where it got out } \\
\text { of hand. Then the division manager became the CEO of ABB. Everybody who wanted to be } \\
\text { something had to talk about Industrial IT and AIP, whether they knew what it was or not ... in } \\
\text { one of the annual reports, ABB was a huge company with about } 200,000 \text { employees, but the only } \\
\text { product mentioned was the Aspect Integrator Platform." }\end{array}$ \\
\hline
\end{tabular}

Note: The highlighted text (bold italics) exemplifies passages from the data that served as basis for the coding. 
Table B3. Phase Transition 3

\begin{tabular}{|c|c|c|}
\hline Construct & Dimension & Illustrative Examples from the Data \\
\hline \multirow{4}{*}{ 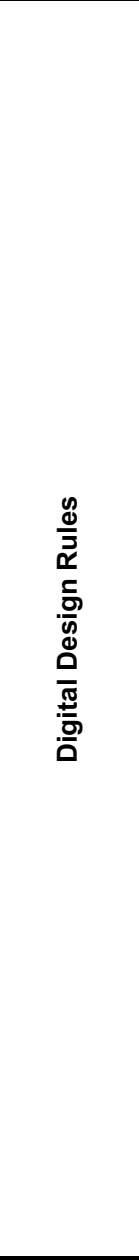 } & $\begin{array}{l}\text { Reprogram- } \\
\text { mability }\end{array}$ & $\begin{array}{l}\text { "800xA Performance Improvements (since 5.1) } \\
\text { - Reduced Engineering New CDE editor, new Batch editor, FD } \\
\text { - Improvements, Electrical Integration, Foundation Fieldbus ... } \\
\text { - More Opportunity Multisystem Integration for larger systems, Asset Optimization, Alarm Mgt, Control } \\
\text { - Room(EOWs), History, SmartClient, new interfaces } \\
\text { - } \text { Mere Communications Interfaces } \\
\text { - } \text { Meduced server computers, Virtualized Servers and clients } \\
\text { - } \text { Fewer Connectivity Servers CS Server footprint } \\
\text { - IEC } 61850 \text { throughput FF Subnets per CS } \\
\text { - Fewer Controllers Required ×2-3 AC } 800 M \text { performance } \\
\text { - IAC for automation and safety } \\
\text { - } \text { More effective deployment of IEC61850 } \\
\text { - } \text { Improved availability Vmware vmotion high availability, sans storage } \\
\text { - Larger system support ×2 no of network areas } \\
\text { - X2 tags in system } \\
\text { - } \text { x2 no of clients, MSI supported features } \\
\text { Fewer cabinets needed, Digital High density S800 I/O, new power supplies," }\end{array}$ \\
\hline & $\begin{array}{l}\text { Data } \\
\text { homogeni- } \\
\text { zation }\end{array}$ & $\begin{array}{l}\text { "ABB has developed a component that bridges this language divide. The Fieldbus Plug (FBP) is a } \\
\text { compact accessory that takes information from equipment in the field and converts it to any industry- } \\
\text { standard protocol. It is, in effect, a translator or interpreter." } \\
\text { "The OPC connectivity that's part of the System 800xA's integration platform enables connection of third- } \\
\text { party DCS controllers and PLCs. Once connected, the data becomes part of the system in the same way } \\
\text { as other integrated ABB hardware and software components." }\end{array}$ \\
\hline & Decoupling & $\begin{array}{l}\text { "A key element of this division's product offering is its System } 800 x \text { A process automation platform. This } \\
\text { product extends the capability of traditional process control systems, introducing advanced functions such } \\
\text { as batch management, asset optimization and field device integration which 'plug in' to a common user } \\
\text { environment. The same user interface may also be used to manage components of existing multiple ABB } \\
\text { control systems that have been installed in the market over approximately the past } 25 \text { years." }\end{array}$ \\
\hline & $\begin{array}{l}\text { Distributed- } \\
\text { ness }\end{array}$ & $\begin{array}{l}\text { At the core of System } 800 x A \text { is its integration platform, which enables ABB to provide a powerful evolution } \\
\text { path for its large installed base of control systems to System 800xA Operations. There are significant } \\
\text { benefits in evolving to the latest hardware and software versions if you own one of ABB's traditional control } \\
\text { systems. However, these benefits extend even further when integrating other equipment such as 3rd } \\
\text { party controllers and PLCs." }\end{array}$ \\
\hline
\end{tabular}




\begin{tabular}{|c|c|c|}
\hline \multirow{4}{*}{ 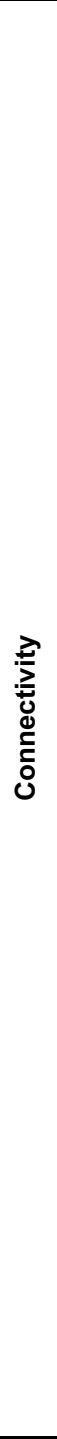 } & $\begin{array}{l}\text { Connected- } \\
\text { ness }\end{array}$ & $\begin{array}{l}\text { "Seamless integration to various ABB and third-party systems: } \\
\text { - } \quad \text { ABB Control Systems: Infi90, Melody, MOD 300, DCl, Freelance, DCI, Satt-line } \\
\text { - Third-party controllers: OPC, Honeywell TDC3000, PLCs } \\
\text { - BatchManagement, AssetOptimization, Device Integration, Information Management } \\
\text { - EnterpriseConnect, CMMSIntegration, VideoOne, Matrikon Alarmlnsights, OPC History Access for } \\
\text { Trends, Documentation." }\end{array}$ \\
\hline & Diversity & $\begin{array}{l}\text { "As a pioneering technology leader in digital solutions, with an installed base of more than } 70 \text { million } \\
\text { connected devices and } 70,000 \text { control systems, ABB is uniquely positioned to support its customers' } \\
\text { digital transformation." } \\
\text { "A consultant that I really respect told us this. Ten years ago, I knew about the whole system. Today, I } \\
\text { understand the controller, the rest I don't understand. Everything is so specialized so you only really } \\
\text { understand your little part. This means that trouble shooting involves ten-twelve persons directly, just } \\
\text { coordinating that is demanding." }\end{array}$ \\
\hline & Adaptiveness & $\begin{array}{l}\text { "A yearly subscription to the Automation Sentinel program provides the following deliverables: } \\
\text { - Licenses for new versions of system software } \\
\text { - Software maintenance updates } \\
\text { - Extended support for System } 800 x A \text { software versions, up to seven years } \\
\text { - Technical phone support to assist in system problem troubleshooting } \\
\text { - On-line website access for downloads to assist in system maintenance } \\
\text { - Software updates } \\
\text { - } \text { Esirmware updates } \\
\text { - Software release notes } \\
\text { - Product technical bulletins } \\
\text { - Software security management: } \\
\text { - Microsoft security patch validation status reports } \\
\text { - Third-party virus scanner qualification } \\
\text { Personal computer hardware qualifications for compatible replacement PC models for new and existing } \\
\text { - Doftware versions } \\
\text { - HART } \\
\text { - Tevice library management updates for System } 800 x A \text { for PROFIBUS, FOUNDATION Fieldbus and } \\
\text { - Product release information" }\end{array}$ \\
\hline & $\begin{array}{l}\text { Mutual } \\
\text { dependencies }\end{array}$ & $\begin{array}{l}\text { "Previously, control systems were developed in-house by different suppliers. More or less everything was } \\
\text { developed in-house, something on all circuit boards, they built and assembled it themselves. Now } \\
\text { Windows is used as a foundation, servers ... and we know what is happening in the world of PCs, } \\
\text { everything spins faster and faster. New operating systems and new versions. And we're seeing this } \\
\text { development in control systems as well. You're forced to update more frequently, even control systems." }\end{array}$ \\
\hline \multirow{3}{*}{ 过 } & $\begin{array}{l}\text { Interaction } \\
\text { rules }\end{array}$ & $\begin{array}{l}\text { "The challenge for manufacturers is that different fieldbus devices often speak entirely different languages, } \\
\text { depending on the standard communications protocol they use. One might use a protocol called DeviceNet; } \\
\text { another Profibus; a third might use the AS-interface protocol. Most devices cannot be interchanged without } \\
\text { modification. ABB has developed a component that bridges this language divide. The Fieldbus Plug } \\
\text { (FBP) is a compact accessory that takes information from equipment in the field and converts it to any } \\
\text { industry-standard protocol. It is, in effect, a translator or interpreter. ABB believes the FBP will have } \\
\text { significant implications for its low-voltage products business, currently worth some } \$ 2 \text { billion a year." }\end{array}$ \\
\hline & Design control & $\begin{array}{l}\text { "Automation Sentinel is the system lifecycle management program that extends support for, and the value } \\
\text { of, existing ABB control systems, protecting our customers' system investments. The program provides the } \\
\text { best overall ROI for past, present and future automation control system software expenditures. The } \\
\text { Automation Sentinel Program assists system owners in actively managing their lifecycle system costs } \\
\text { and investments. With this program, system owners can decide when to update to newer versions of } \\
\text { system software based on their system lifecycle plan and business objectives. In addition, customers } \\
\text { receive consistent support through the complete lifecycle of their system." }\end{array}$ \\
\hline & $\begin{array}{l}\text { Stimuli- } \\
\text { response } \\
\text { variety }\end{array}$ & $\begin{array}{l}\text { "There is a constant flow of upgrades from ABB's side, not only from them actually but also from } \\
\text { Microsoft, a lot of security-related updates.' Most updates are done to avoid problems, but there are of } \\
\text { course also improvements in functionality. Between versions four and five for example, there are functional } \\
\text { improvements. But there are also minor ones and service packs, they are often corrections when they } \\
\text { discover problems." }\end{array}$ \\
\hline
\end{tabular}

Note: The highlighted text (bold italics) exemplifies passages from the data that served as basis for the coding. 


\section{Appendix C}

Table C1. A Functional Model of Process Production Systems: The Purdue Reference Model as Applied in ISA-99 (adapted from CISCO 2013)

\begin{tabular}{|c|c|c|}
\hline Zone & Layer & Description \\
\hline \multirow{2}{*}{ 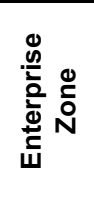 } & $\begin{array}{l}\text { Level 5: Enterprise } \\
\text { Network }\end{array}$ & $\begin{array}{l}\text { Centralized IT systems and functions, Enterprise Resource Management, business-to-business and } \\
\text { business-to-customer services }\end{array}$ \\
\hline & $\begin{array}{l}\text { Level 4: Site } \\
\text { Business Planning }\end{array}$ & $\begin{array}{l}\text { Extension of the enterprise network, basic business administration performed through standard IT } \\
\text { services. Access to internet, e-mail and enterprise applications. Non-critical plant systems such as } \\
\text { manufacturing execution systems and plant reporting such as inventories. }\end{array}$ \\
\hline \multicolumn{3}{|c|}{ Demilitarized Zone: Provides a buffer zone where services and data can be shared between Manufacturing and Enterprise zones } \\
\hline \multirow{4}{*}{ 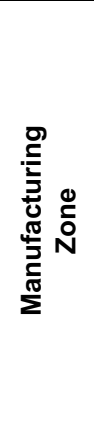 } & $\begin{array}{l}\text { Level 3: Site } \\
\text { Manufacturing } \\
\text { Operations and } \\
\text { Control }\end{array}$ & $\begin{array}{l}\text { The highest level of the distributed control system, manages plant-wide automation functions. Reporting } \\
\text { data such as cycle times and predictive maintenance, detailed production scheduling, asset and material } \\
\text { management, control room workstations, patch launch server, file server. Applications primarily based } \\
\text { on standard computing equipment and operating systems. }\end{array}$ \\
\hline & $\begin{array}{l}\text { Level 2: Area } \\
\text { Supervisory } \\
\text { Control }\end{array}$ & $\begin{array}{l}\text { Applications and functions associated with supervision and operation of each area such as operator } \\
\text { interfaces, alarms, and control room workstations. Communicates with controllers in level } 1 \text { and shares } \\
\text { data with levels } 3 \text { and/or } 4 \text { and } 5 \text { via the DMZ. }\end{array}$ \\
\hline & $\begin{array}{l}\text { Level 1: Basic } \\
\text { Process Control }\end{array}$ & Controllers that steer automation of the process based on input from level 0. \\
\hline & Level 0: Process & $\begin{array}{l}\text { Input and output units such as sensors and actuators that measure and perform the functions of the } \\
\text { manufacturing system. Solutions that can operate without alteration for extended periods. }\end{array}$ \\
\hline
\end{tabular}

\section{Reference}

CISCO. 2013. Converged Plantwide Ethernet (CPwE) Design and Implementation Guide (http://www.cisco.com/en/US/docs/solutions/ verticals/CPwE/CPwE_chapter2.html\#wp1002608; accessed February 6, 2013). 
Appendix D

\begin{tabular}{|c|c|c|c|c|}
\hline Characteristic & Phase 1: Master & Phase 2: Advant & Phase 3: AIP & Phase 4: $800 \times A$ \\
\hline $\begin{array}{l}\text { Platform } \\
\text { Description }\end{array}$ & $\begin{array}{l}\text { New functionality for } \\
\text { reducing complicated } \\
\text { interactions among } \\
\text { physical devices. }\end{array}$ & $\begin{array}{l}\text { New functionality for } \\
\text { reducing complicated } \\
\text { interactions among specific } \\
\text { information management } \\
\text { components through tight } \\
\text { coupling. }\end{array}$ & $\begin{array}{l}\text { New functionality for } \\
\text { taming complexity asso- } \\
\text { ciated with connectivity } \\
\text { among non-specified } \\
\text { information management } \\
\text { components through loose } \\
\text { coupling. }\end{array}$ & $\begin{array}{l}\text { New functionality for } \\
\text { interactions with foreseen } \\
\text { and unforeseen agents } \\
\text { and assets in the } \\
\text { ecosystem. }\end{array}$ \\
\hline $\begin{array}{l}\text { Participating } \\
\text { agents }\end{array}$ & $\begin{array}{l}\text { Firm (mainly division level) } \\
\text { due to internal design and } \\
\text { manufacturing. }\end{array}$ & $\begin{array}{l}\text { Firm (mainly division level) } \\
\text { and strategically selected } \\
\text { suppliers (HP, Unix, } \\
\text { collection of information } \\
\text { system providers). }\end{array}$ & $\begin{array}{l}\text { Firm level and ecosystem } \\
\text { with certified external } \\
\text { agents. }\end{array}$ & $\begin{array}{l}\text { Unbounded and dynamic } \\
\text { ecosystem of agents with } \\
\text { large variations in } \\
\text { contextual anchoring. }\end{array}$ \\
\hline $\begin{array}{l}\text { Innovative } \\
\text { capabilities }\end{array}$ & Firm capabilities. & $\begin{array}{l}\text { Firm, suppliers, Unix } \\
\text { developers, and selected } \\
\text { information management } \\
\text { system providers. }\end{array}$ & $\begin{array}{l}\text { Potentially unlimited pool } \\
\text { of external capabilities. }\end{array}$ & $\begin{array}{l}\text { Potentially unlimited pool } \\
\text { of external capabilities. }\end{array}$ \\
\hline $\begin{array}{l}\text { Nature of } \\
\text { interfaces }\end{array}$ & $\begin{array}{l}\text { Fixed and closed, one- } \\
\text { to-one mapping. } \\
\text { - Focused on physical } \\
\text { setting. }\end{array}$ & $\begin{array}{l}\text { Adapted to internalize } \\
\text { data from external } \\
\text { systems, one-to-one } \\
\text { mapping. } \\
\text { Focused on engineering } \\
\text { (site configuration). }\end{array}$ & $\begin{array}{l}\text { APl's and adaptation } \\
\text { module to exchange } \\
\text { data, many-to-many } \\
\text { mapping. } \\
\text { Core of the firm's } \\
\text { ecosystem-based } \\
\text { business strategy. }\end{array}$ & $\begin{array}{l}\text { Based on general } \\
\text { purpose IT standards, } \\
\text { many-to-many } \\
\text { mappings. } \\
\text { Focused on connec- } \\
\text { tivity within and across } \\
\text { sites, and toward } \\
\text { general purpose IT } \\
\text { components. }\end{array}$ \\
\hline Architecture & $\begin{array}{l}\text { Device modularization } \\
\text { and loose coupling in } \\
\text { physical environment } \\
\text { between devices and } \\
\text { networks. } \\
\text { Vertical increase in } \\
\text { connectedness at PRM } \\
\text { levels 0-2 (Process, } \\
\text { Basic Process Control, } \\
\text { Area Supervisory } \\
\text { Control). }\end{array}$ & $\begin{array}{l}\text { Services and devices } \\
\text { loosely coupled to } \\
\text { increase adaptiveness } \\
\text { toward general purpose } \\
\text { IT components, tight } \\
\text { coupling between } \\
\text { services and content. } \\
\text { - Increases in connected- } \\
\text { ness horizontally at PRM } \\
\text { levels 0-2 (Process, } \\
\text { Basic Process Control, } \\
\text { Area Supervisory } \\
\text { Control), and vertically } \\
\text { toward level } 3 \text { (Site } \\
\text { Manufacturing } \\
\text { Operations and Control). }\end{array}$ & $\begin{array}{l}\text { Loose coupling } \\
\text { between services and } \\
\text { content, and among } \\
\text { services. } \\
\text { - Vertical and horizontal } \\
\text { increases in connected- } \\
\text { ness, PRM levels } 4 \\
\text { (Site Business } \\
\text { Planning) and } 5 \\
\text { (Enterprise Network) } \\
\text { added. }\end{array}$ & $\begin{array}{l}\text { Tight coupling to } \\
\text { Windows OS. Open } \\
\text { and disclosed inter- } \\
\text { faces, shared } \\
\text { standards. } \\
\text { Horizontal expansion in } \\
\text { connectedness at user } \\
\text { sites. Vertical expan- } \\
\text { sion toward (e.g., } \\
\text { remote clients). Lateral } \\
\text { expansion toward the IT } \\
\text { industry. }\end{array}$ \\
\hline Governance & $\begin{array}{l}\text { Design decision rights } \\
\text { and control retained } \\
\text { internally. }\end{array}$ & $\begin{array}{l}\text { Design decision rights } \\
\text { and control retained for } \\
\text { hardware in PRM level } 1 \\
\text { (Basic Process Control) } \\
\text { but distributed to sup- } \\
\text { pliers for level } 2 \text { (Area } \\
\text { Supervisory Control). } \\
\text { For software integration } \\
\text { high levels of distribution } \\
\text { due to tight couplings } \\
\text { that ABB has to } \\
\text { maintain. }\end{array}$ & $\begin{array}{l}\text { Attempts to implement } \\
\text { formal input control } \\
\text { measures through } \\
\text { certification program } \\
\text { and decrease } \\
\text { dependencies on } \\
\text { components with } \\
\text { distributed decision } \\
\text { rights. }\end{array}$ & $\begin{array}{l}\text { Significant decision } \\
\text { rights distributed to } \\
\text { Microsoft. Input control } \\
\text { through substantial } \\
\text { testing and certification } \\
\text { of software versions. }\end{array}$ \\
\hline
\end{tabular}


